\title{
How do Consumers' Gender and Rational Thinking Affect the Acceptance of Entertainment Social Robots?
}

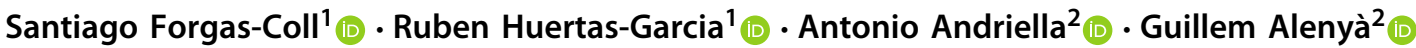

Accepted: 19 November 2021 / Published online: 19 December 2021

(c) The Author(s) 2021

\begin{abstract}
In recent years, the rapid ageing of the population, a longer life expectancy and elderly people's desire to live independently are social changes that put pressure on healthcare systems. This context is boosting the demand for companion and entertainment social robots on the market and, consequently, producers and distributors are interested in knowing how these social robots are accepted by consumers. Based on technology acceptance models, a parsimonious model is proposed to estimate the intention to use this new advanced social robot technology and, in addition, an analysis is performed to determine how consumers' gender and rational thinking condition the precedents of the intention to use. The results show that gender differences are more important than suggested by the literature. While women gave greater social influence and perceived enjoyment as the main motives for using a social robot, in contrast, men considered their perceived usefulness to be the principal reason and, as a differential argument, the ease of use. Regarding the reasoning system, the most significant differences occurred between heuristic individuals, who stated social influence as the main reason for using a robot, and the more rational consumers, who gave ease of use as a differential argument.
\end{abstract}

Keywords Social-robot acceptance $\cdot$ Entertainment $\cdot$ Gender differences $\cdot$ Reasoning system $\cdot$ Dual-process theory

\section{Introduction}

A robot has been defined as "an autonomous machine capable of sensing its environment, carrying out computations to make decisions, and performing actions in the real world" [1]. Although designing robots for service use began a long time ago $[2,3]$, the prototypes developed were quite rigid, as they were oriented towards following rules and individuals had to adapt to the machine [4]. It was not until the last decade that, thanks to the developments in artificial intelligence and

Santiago Forgas-Coll

Santiago.forgas@ub.edu

Ruben Huertas-Garcia

rhuertas@ub.edu

Antonio Andriella

aandriella@iri.upc.edu

Guillem Alenyà

galenya@iri.upc.edu

1 Business Department, University of Barcelona, Avda. Diagonal, 690, 08034 Barcelona, Spain

2 Institut de Robòtica i Informàtica Industrial CSIC-UPC, C/Llorens i Artigas 4-6, 08028 Barcelona, Spain machine learning algorithms, robotics has progressed in a significant way in terms of increasing the apparent autonomy of robots [5] and with a shift in focus towards social robotics [4].

Social robotics aims to provide robots with a simple and intuitive interface that allows them to deal with the complexity required to carry out interactions with humans. Pillinger [6], completing Weber's [4] proposal, considered that three types of relationships with social robots currently predominate: between caregiver and child/baby, between owner and his/her pet, and with sex robots.

All these technological advances have coincided in time with significant demographic changes, derived from a rapid ageing of the population, a longer life expectancy and the elderly having an increasing desire to lead an independent life [7]. Social changes that put strong pressure on the healthcare system and are boosting the demand for animatronics capable of fulfilling assistive and entertainment functions. The global market for these robots is expected to reach USD 3.71 billion by 2023 at a CAGR of $23.06 \%$ from 2018 to 2023 . Entertainment and companion robots, designed for leisure purposes, would be close to the relationship classified by Weber as owner-pet. These robots can interact with people 
by singing, dancing, playing games, facilitating communication with relatives and, in general, preventing loneliness [8]. In addition, they can also be used in education, information and communication, hospitality, and health and social care [9]. An example is the robot "Spencer", used by KLM to guide passengers at Amsterdam's Schiphol airport [10].

Acceptance of social robots involves a new experience for consumers, which is redefined through human-robot interaction (HRI). HRI is an interdisciplinary field of study covering robotics, artificial intelligence, cognitive sciences, psychology, ethology (part of biology) and sociology [4] dedicated to understanding, designing and evaluating robotic systems, exploring the human factors that make it possible to achieve quality relationships and, ultimately, accomplish a symbiosis between humans and robots [11]. If the performance of industrial robots is measured by their efficiency, the success of service robots depends on users' satisfaction [12]. Therefore, before launching a social robot for entertainment, it is essential to understand the variables that induce greater acceptance [13].

To analyse the process of acceptance of new technologies, models derived from social psychology have been used. One of the first was the Technology Acceptance Model (TAM) proposed by Davis [14], which is based on the theories that prevailed at that time, that is, the Theory of Reasoned Action [15] and the Social Cognitive Theory [16]. As new technologies progressed, so did the theory and users' familiarity with their use. Therefore, new models, such as the Unified Theory of Acceptance and Use of Technology (UTAUT), attempted to respond to the new environmental challenges $[17,18]$. This model, developed to accommodate a more advanced state of technological development, of an eclectic nature, achieved greater predictive capacity. Therefore, some researchers have considered UTAUT a more integrative proposal than TAM and other theories of technology adoption [19]. However, although they are models that are intended for generalist purposes, their application in the field of robotics is complex, since robotic technology is far more sophisticated than that required by other technological devices [20, 21]. Indeed some researchers have argued that robots should be considered a new technological genre [22].

Only a few studies have tested technological acceptance models for the case of social robots. The best known is the Almere model, which is an adaptation of the UTAUT model to study the acceptance of social robots in elderly-care contexts [23]. And, more recently, other researchers have tested an extension of the Almere model in health-care settings and what they have called RAM-care [24]. Although these models offer useful information about the factors that influence the acceptance of social robots, the use of excessively artificial scenarios makes it difficult to generalise and adapt them to other contexts. Many studies use Wizard-of-Oz (robot manipulated by an operator, not autonomous) settings [23,
$25]$ or video images $[26,27]$ that show interactions that are far removed from reality. Suchman [28] criticised the false sensation generated by these scenarios and underlined the need to assess real experiences with social robots, even in the lab, since real interactions are far less accurate than those shown in videos.

Yet, not everyone has the same predisposition towards new technologies. One of the most analysed and controversial characteristics of the new technologies is the different degree of acceptance that prevails between genders [29]. Literature on HRI has been criticised for treating gender issues uncritically and without taking an inclusive approach, as well as reproducing heteronormative and binary gender stereotypes without distinguishing between sex and gender [6,30]. Thus, some studies on HRI show that men, compared to women, state a greater preference towards robots [11], see them as more useful and have a greater intention to use them in the future [31]. In addition to not differentiating between sex and gender, none of these studies support the causes of gender difference in any nativist theories [32], practically all of them taking an environmentalist theoretical background as their starting point $[16,33]$.

At the same time, some researchers have proposed that humans use a dual-process information system: one autonomous and intuitive and the other more deliberative and analytical [34, 35]. The use of one system or the other determines the decision process. For example, the use of an analytical thinking system can increase subjects' disbelief towards phenomena that are extraordinary or difficult to explain [36]. Other researchers have also proposed dual-process theory as a basic criterion for assessing the truthfulness of facts, regardless of whether they are consistent or inconsistent with the ideology they have already formed [35]. We believe that the dual-process theory can be a key factor in the acceptance of social robots.

This study has a double objective: first, to propose and test a parsimonious technological acceptance model for the case of social robots after a real entertainment experience, based on the UTAUT. Second, we put forward the idea of segmentation, in the sense that not all users (male and female, more rational or heuristic) will express the same degree of acceptance of new robot prototypes.

The paper proceeds as follows. First, a review of the literature that leads to the proposed research model and hypothesis justification is provided. Second, the research methodology, data analysis and results are presented. Finally, it concludes with a discussion about research and its practical implications. 


\section{Theoretical Background and Research Model}

Despite the progress made by industrial robots in the automation processes of routine and dangerous tasks for decades, attention has only shifted towards the development of service robots in the last ten years [5]. These robots have many possibilities and applications include their domestic use, such as the robot vacuum cleaner, use in hospitals as in the case of robots that carry medication, or in tourist services, such as the robot receptionist [37]. However, given that one characteristic of services is the high degree of contact between service providers and customers during the service [38], it is foreseeable that frequent HRI will also occur with service robots.

Social robotics is the field responsible for the study of robots' ability to interact and communicate with other robots, with humans and with the environment [39]. Taking into account humans' unconscious ability to attribute agency, personality and intentionality to computer-mediated technologies [20], the study of HRIs implies understanding the subjective perceptions that users have about what robots are, how they work and what they can or cannot do, so that their experience leads them to satisfaction [12]. One of the key elements of social robotics is to analyse how their physical appearance (i.e. mechanoid, humanoid or android) affects users' perception about their social abilities [37, 40]. There seems to be a tendency to anthropomorphise the machines with which humans interact socially, in entertainment and home environments they are assigned female, baby or pet shapes [4], since male forms can be perceived as threatening [26]. In fact, Suchman [28] considered that the key attributes to endow a machine with humanity are embodiment, emotion and sociability. In the case of anthropomorphic robots, HRI has been considered as if it were a between-human relationship [27, 41]. For example, the fact that a robot shows a more social or kinder condition has a similar effect to that of humans when they behave in a more social or kinder manner $[8,23]$. That is, the degree of anthropomorphism of the robot will have an effect on user perception.

From the consumer's perspective, the comprehension of a new technology, such as social robots, is usually more the result of their social activity than their scientific, technological or industrial knowledge [20, 42]. In other words, how individuals understand and value a technology is directly related to the prevailing social attitude towards that technology. Consequently, the social position of each individual, their culture, gender, social class, intellectual capacity, age, etc. contribute to the way in which robots are considered as social entities in everyday situations [37].

All these precedents highlight the importance of social influence in technological acceptance. Consequently, to study the acceptance of a semi-humanoid robot in the context of entertainment services, we propose to work with models derived from social psychology, which is the field of social sciences that studies the influence that the real, imaginary or symbolic presence of other people has on people's thoughts, feelings, perceptions, motives and behaviours [43].

\subsection{Social Robots for Entertainment}

A social robot is one that has the ability to communicate and interact with humans and other autonomous physical agents, autonomously and following social rules. Currently, most social robots are prototypes that need to be operated by humans, but advances in artificial intelligence, codified ethics and improvements in sensor technology are increasing their degree of autonomy [44]. In addition, these robots are designed for keeping company and for entertainment, which means involving users physically, cognitively and emotionally both inside and outside the home, and having an anthropomorphic appearance is particularly relevant in this case [45]. In both humanoids and droids (android or gynoid for women), the design of their physical appearance is related to the type of tasks they can perform [46]. For example, while security robots are designed as male, domestic robots are given female characteristics. These applications that reproduce gender stereotypes in social robots have been criticised, as has the fact of trying to bring humanoid robots into homes [6, 47]. Robertson [30] even considered the introduction of humanoid social robots to be the vanguard of post-human sexism developing in a reactionary rhetoric. In her study of Japanese society, characterised by a pronounced labour shortage, a flat birth rate and an ageing population, humanoid robots are preferred over immigrants to care for children and the elderly and to help with housework. Moreover, their application in homes to perform household chores aims to make the traditional family model more attractive for women and thus encourage them to become pregnant and serve as machines for giving birth (to future workers) rather than to pursue their own professional careers [30].

On the other hand, although often confused, droids have a far more realistic human appearance than humanoids, which have forms that are simpler, more stylised or similar to cartoon representations of the human form. Although people who interact with humanoids immediately recognise their human appearance, since they have a head, facial features, eyes, ears, eyebrows, arms, hands, legs, etc. [48], it is also important to exhibit social skills to facilitate natural communication [49]. That is, in addition to its physical appearance, it must use communication protocols, combining verbal and kinetic (non-verbal) channels, capable of being adapted to meet the user's information needs so as to convey the feeling of having a fluent conversation [50]. Consequently, we cannot expect individuals who have experienced an HRI with a 
humanoid social robot to respond in the same way as when dealing with other technologies [20, 37].

\subsection{Technological Acceptance of Social Robots}

Based on social psychology, technological acceptance models have been developed that attempt to analyse and relate informational factors that explain how users accept and use a new technology. Although there are many [51], we are going to introduce those that have become the most relevant in HRI $[22,23]$. One of the pioneers was the Technology Acceptance Model (TAM), developed by Davis [14], and based on the proposals made by the Theory of Reasoned Action (TRA) [15] and by the Social Cognitive Theory (SCT) [16]. Davis [14] proposed TAM from a utilitarian perspective and considering a work environment. The intention to use the new technology depended on the perceived usefulness (how this technology improves work efficiency) and the perceived ease of use (how easy it is to use this technology), both of which are components of attitude. In addition, he considered that this relationship could be moderated by external variables, such as age, gender, etc. Although the TAM model was studied for more than a decade and underwent numerous modifications, changes in theoretical paradigms (Theory of Planned Behaviour proposed by Ajzen) [51] and consumers' greater familiarity with such devices led the model to become the Unified Theory of Acceptance and Use of Technology (UTAUT) [17, 18]. It is an eclectic model, which combines theoretical foundations and empiricism, and due to its greater predictive capacity, it is considered a more integrative model than TAM and has imposed itself upon the other theories of technology adoption [19].

Although more advanced models such as the UTAUT-2 [18] have been proposed, they are better suited for use in an environment of market maturity and widespread familiarity on the part of consumers (computers, mobile phones). The UTAUT can be a good basis for developing models of technological acceptance of social robots for two reasons. First, although the TAM model could be considered the most appropriate at an introductory stage, social robots, due to their embodiment and social skills, are completely different from other technological devices, such as laptops or smartphones [23, 52]. As noted above, the TAM model considers that the intention to use depends exclusively on its cognitive evaluation (perceived usefulness and perceived ease of use), which is deemed appropriate in the context of industrial robotics. For example, Bröhl et al. [53] proposed an adaptation of the TAM model to study how industrial workers accept sharing their task with a robot (the acceptance of human-robot collaboration) and, furthermore, analysed differences in the degree of acceptance in four countries (Germany, Japan, China and the United States). Second, when a social robot acts by offering a service, it should not only provide the core of the service, but also add value with socioemotional and relational elements [54]. That is, the core of the service generally relates to functional outcomes, while the relational form (a female/male voice, the tone of the conversation) is linked to its social outcomes [55]. This view is in line with that of Heerink et al. (2010) [23], who extended the TAM by including a number of socio-emotional and relational variables in the context of elderly care. Ultimately, the UTAUT seems more suitable for service delivery than the TAM

According to UTAUT the intention to use a new technology, such as an entertainment social robot, is explained by four constructs: Performance Expectancy (a new name assigned to TAM's Perceived Usefulness), Effort Expectancy (a new name for TAM's Perceived Ease to Use), Social Influence and Facilitating Conditions. In addition, it is moderated by user characteristics (Gender, Age, Experience and Voluntariness of Use). The UTAUT represented an improvement of the TAM by incorporating two new constructs: the perceived social influence, which represents the degree of acceptance that an individual receives from his/her social environment when using the new technology, and the Facilitating Conditions, that is, the individual's perception of their degree of control over this new technology. These modifications represented an adaptation to the Theory of Planned Behaviour and an improvement in the theoretical basis.

There are numerous precedents for studying the technological acceptance of social robots, and they have been conducted within a wide range of services and scenarios. These scenarios range from text descriptions, video representations and, more realistically, Wizard-of-Oz scenarios [51]. The outcomes of front-office services are experiences, and social robots, with their ability to generate social interaction during the customer encounter, contribute to co-creating this experience [55]. The use of social robots in different services and with different degrees of abilities to interact with customers will result in different experiences [55]. This study, to our knowledge, is the first to evaluate the technological acceptance of an entertainment robot after undergoing a direct, face-to-face experience and having a conversation, including messages giving advice and encouragement (as recommended by Suchman [28] and Savela et al. [51]).

In order to study users' attitude or intention towards robots, on the one hand, it is necessary to take into account their degree of accessibility. This refers to the degree of intensity of the relationship between the evaluating subject (user) and the object of evaluation (the robot) [43]. And, one way to achieve greater accessibility is to have a direct experience, rather than to do so indirectly through other users' comments or published information. This direct experience results in more extreme and less ambivalent ratings [43, 51]. Similar results have been obtained in robotics research [23, 57]. For example, Savela et al. (2018) [51] found that in studies of 
robot technology acceptance, when participants rated hypothetical experiences, they were more likely to report negative attitudes than when exposed to real robots, whose ratings were more positive. When people lack first-hand experience with robots, they must base their ratings on social representations or mental images stored in memory, which affect not only the degree of intensity but even the direction of the attitude $[43,51]$.

On the other hand, while a first impression contributes significantly to the formation of a general idea about HRI, it is not sufficient to be able to appreciate all the relevant factors involved, as accessibility also requires more experiences [43]. Therefore, after a first brief experience, it is better to propose to participants the evaluation of a parsimonious model (with few factors), but with the essential elements, rather than a more complex model with relationships that they will not have had enough time to appreciate and internalise [43]. But what are the essential elements that the model should include? According to social psychology proposals, they are cognitive, affective and behavioural elements [43].

Taking into account the above considerations and the context of a still developing social robot technology, a parsimonious model is proposed to evaluate users' technological acceptance after a real entertainment experience [58]. Although the proposal is based on the UTAUT, it must take into account the three essential elements proposed by Gerrig [43], adapted to the technological acceptance of social robots. The three elements are: functional (perceived usefulness and perceived ease of use), socio-emotional (social influence) and relational (perceived enjoyment) [55]. Thus, given that the service provided by the robot is to entertain, perceived enjoyment has been incorporated into the model and, due to the nascent stage in which social robotics currently find itself, the use of the Facilitating Conditions construct does not make sense until consumers become more familiar with it, so it has been removed. The proposed model is defined by the following hypotheses:

H1. The perceived usefulness of using an entertainment robot is positively related to the intention to use it.

H2. The perceived ease of use of an entertainment robot is positively related to the intention to use it.

H3. The perceived enjoyment of the use of an entertainment robot is positively related to the intention to use it.

H4. The social influence of the use of an entertainment robot is positively related to the intention to use it.

H5. The perceived ease of use of an entertainment robot is positively related to the perceived usefulness.

\subsection{User Gender}

Consumer gender is frequently used both as a basic criterion for product and service segmentation [56] and in communication and advertising campaigns [59]. In fact, gender is one of the most widely used segmentation factors, as it is easy to identify, accessible and the segments generated are broad enough to be cost-effective [56]. This practice is based on the assumption that men and women have different cognitive structures, personality traits and interests associated with their gender roles, which guide their judgements and decision-making processes [60]. Under this belief, enterprises such as the Coca-Cola Company have designed products with almost the same ingredients, Coca-Cola Zero and Diet Coke, the former targeting male consumers and the latter targeting female consumers of zero-calorie soft drinks [61].

The literature on HRI has also addressed the gender issue from different perspectives. Nomura [11] proposed a classification of these studies into three categories: i) implications of the male, female or neutral gender of robots in users' acceptance [26, 62]; ii) acceptance of robots according to the user's gender [8]; and iii) interaction effects between the genders of robots and users [27]. All these perspectives have been criticised both for not differentiating between sex and gender, and for reproducing heteronormative and binary gender stereotypes $[8,30]$. That is, while sex is formed by the biological nature of the human body, gender refers to the stereotyped characteristics related to social expectations about behaviours, attitudes and preferences that are considered adequate or inappropriate $[6,56]$.

Furthermore, it has also been pointed out that reducing the analysis of participants to their sex or gender leads to an excessive emphasis on gender differences, neglecting other relevant factors such as age, socioeconomic level, experience, etc. [6]. For example, Wang and Young [8] highlighted the under-representation of women in science and engineering and even as participants in HRI studies. They also criticised the oversimplification that the gender dichotomy implies and advocated for greater sensitivity in order to achieve more nuanced results, while also proposing some advice on how to accomplish an inclusive approach [8]. Later, Rea et al. [25] carried out a study that replicated other studies that use gender stereotypes with the aim of trying to validate these stereotypes or show them to be false. Mixed results were obtained: while some stereotypes such as male participants being less polite than females towards robots were validated, others such as women's lower commitment or greater concern with robots were disproved. However, the test conducted by Rea et al. [25] used small samples and only considered gender, ignoring any other factor.

This controversy stems from the ongoing debate among psychologists regarding the different behaviour of men and women, that is, whether these differences are mainly due to genetic-biological inheritance (nature) or environmental influence (nurture) [56,63]. A wide range of theories attempt to explain the causes of these differences, ranging from the extreme nativists (those who believe that genetic, hormonal 
and brain structure influences are responsible for different behaviours) [32] to the extreme ecologists (who attribute them to the socio-cultural environment, stereotypes and the media) [16, 33].

According to nativist theories, the basis for behavioural differences between the sexes is due to chromosomal and hormonal differences, as well as differences in brain structure and cognitive processes [43, 56]. Among the hormonal differences, testosterone plays a key role in determining the sex of a newborn and also affects mood formation and personality. In particular, androgynous differences affect their interests, activities and levels of aggression [64]. The fact that these differences emerge at a very early age and are found in all cultures suggests the involvement of biological factors [65]. But, in addition, technical advances in brain scanning have also detected structural differences between males and females. For example, the use of MRI to analyse sex differences in the orbitofrontal cortex revealed that women have a larger volume in regions related to emotional and affective regulation than men [64]. Evidence has also been collected on the different ways in which men's and women's brains work to perform cognitive and emotional tasks. For example, Canli, Desmond and Gabrieli (2002) [66] showed that men and women activated different neural circuits to encode stimuli in memory, in this case the stimuli consisting of funny and neutral images. The results showed that, in general, women recalled the funny images stored in memory with more humour than men, and the explanation had to do with the greater number of brain regions activated both during the viewing of the more emotional images and during subsequent recall.

In summary, while decades ago biological differences between the sexes were considered to have little impact on their behaviour [56], recent research is changing that view by uncovering significant differences in brain activity. In the prefrontal cortex, men, compared to women, produce more neural activity to achieve the same behaviour, in line with the neural efficiency hypothesis. According to this hypothesis, the more intelligent (IQ) produce less neural activity than the less intelligent to perform the same cognitive task. In addition, evidence has been collected showing that in visual processing regions, males report higher activity than females in storing and retrieving realistic visualisations from long-term memory. Finally, gender differences in parahippocampal cortex activity have also been found, for example, greater use of verbal strategies by females than males [64].

According to the ecological school of thought, gender role is a social construct. First, children identify themselves with a gender (usually their own) and then, through the learning process, try to make their identification congruent with the norms of behaviour, motivations and feelings they perceive as appropriate for that gender $[43,56]$. Within this school of thought, several theories have been proposed, one of the most prominent being social role theory [67]. According to this theory, differences between men and women in skills and personality traits often reflect traditional gender roles in society. Thus, men are guided by agentic goals that emphasise assertiveness, self-efficacy and dominance. In contrast, women are guided by communal concerns that emphasise interpersonal affiliation and harmonious relationships [56].

Today, controversy continues to rage over the origins of the behavioural gender difference, as there are: (1) researchers who argue for a decisive socio-cultural influence on the formation of behavioural patterns [33, 67], (2) those who emphasise biological factors $[64,65]$ and (3) those who believe that the truth must lie somewhere between nature and nurture $[68,69]$. One of the theoretical streams that recognises the influence of both biological and socio-cultural factors is evolutionary psychology. As its name suggests, this theory adopts the Darwinian principles of natural and sexual selection that ensure the survival of the species. According to its precepts, behaviour is due to the existence of adaptive programmes, the results of human evolution, which have taken root in the brain and reflect the overcoming of different survival challenges faced by our hunter-gatherer ancestors over thousands of generations [70]. For example, biology has endowed women with the ability to procreate, and they have ancestrally had to raise their offspring in a hostile environment. Thus, those women who invested more in affection and care for their children and, in addition, developed cognitive skills to detect dangerous situations may have promoted their survival and gained an evolutionary advantage [71, 72]. In addition, these programmes acquired over thousands of years take time to change, resulting in temporary mismatches between the prevalence of ancestral behaviours and a modern environment, which are called "evolutionary delays" [73].

Since hunter-gatherer societies still survive, it has been possible to conduct ethnographic studies on their traditions and customs, which have shed light on our ancestors' behaviours (an example is Hill and Hurtado [74]). A prominent feature of these societies is labour division between genders, so while men have the main task of hunting and defence, women are engaged in gathering, reproduction and the care of offspring [75]. This is one of the most controversial and contentious issues among different theoretical currents [67]. For example, social role theory suggests that labour division between sexes creates gender role expectations that lead to differences in social behaviour and personality. Thus, men are more assertive and aggressive because they have historically been more likely to assume leadership positions, while women do not develop these characteristics because they do not play these roles [67]. This explanation contrasts with that provided by evolutionary psychology. According to DeVore and Tooby [76], this labour division that assigns the most dangerous tasks to men is the most efficient for promoting group survival. 
This separation of tasks for thousands of generations has led to the formation of differences in physical characteristics (greater physical strength and size in men) and in perceptual and cognitive skills (ways of processing information) between genders. Thus, a study conducted in 40 countries and with seven ethnic groups showed that women, as a result of their adaptation to gathering, have developed a better memory for remembering the spatial location of objects, while men, as an adaptation in hunting animals, have developed better navigation, map-reading and three-dimensional mental rotation skills [77]. And, although it has been shown that spatial skills can be improved with practice, this does not eliminate the male advantage in these skills [78].

To analyse how these cognitive gender differences affect the intention to use a social robot, this paper proposes that it is necessary to study their effect on antecedents or explanatory factors from an eclectic theoretical perspective. In other words, we need to know how the different cognitive abilities of men and women can affect the perception of usefulness, ease of use, perception of enjoyment and social influence and their effect on the intention to use. In studies on technological acceptance, significant differences have been detected between men and women, the latter being more reluctant to accept technological innovations than men [29, 79]. Even in one of the most widespread technologies, such as the use of the Internet, women make less intensive use of it than men [80]. The literature has compiled several explanations for this behaviour: women perceive themselves as being less skilled, having less control over new technologies [8, 81] and encountering greater difficulties to understand them than men [79, 82]. Even in the search for information they believe they are less effective than men [83]. All this has led, in the most advanced models of technological acceptance, to consider gender as a moderating variable, although without any theoretical support [17].

Similar findings appear in the acceptance models of social robots. For example, Nomura et al. [57] showed that women had more negative attitudes than men and, in another experiment, Nomura et al. [84] also found that women had more negative attitudes towards the social impact of robot implementation. In another study conducted in Taiwan on how parents perceive educational robots, results showed more negative attitudes in mothers than in fathers towards entrusting their children's education to robot machines [85]. However, in the second study there may be a problem of confounding factors, since the degree of acceptance of robots can be confused with the difference in parenting styles between men and women [59]. Regardless of these results, for both researchers and practitioners in social robotics, it is essential to know how men and women differ in their cognitive processes, affective responses and reactions to robot stimuli in order to adjust robots to their preferences and to be able to initiate a process of market segmentation.
Meyers-Levy and Stemthal [68] established some of the different cognitive abilities between genders. In their relationship with the environment, women capture and process more information, in a more comprehensive and enveloping way than men. This ability is due to the fact that they have a lower perception threshold, which allows them to capture information that is unnoticeable to men, such as the perception of non-verbal emotions and the ability to develop a deeper understanding of emotions [62]. In other words, women will pick up non-verbal language better than men, and will also be more sensitive to possible risk signals from the robot, whereas men will pick up less non-verbal language and will not be aware of low-risk signals coming from the robot [86].

On the other hand, men perceive and process information with greater focus, are more selective in stimuli and pay attention to pieces of information that they consider more relevant, while women tend to process information more comprehensively [59, 79]. These different cognitive abilities have resulted in a greater preference for instrumentality [87] and the usefulness of objects in men than in women [88, 89]. Thus, we can predict that in the case of acceptance of entertainment robots:

H6. For women, perceived usefulness will be a less important precedent of the intention to use the robot than for men.

Since women have a greater ability to scan the environment and gather information (for example, they scrutinise with greater eye fixations) than men, this competence has its advantages and disadvantages. On the one hand, this ability allows them to better recognise the environment, to have a global vision and to quickly grasp the robot's possible subtle gestures of danger but, conversely, makes it difficult to establish quick relationships between objects [90] and, consequently, to elucidate the intrinsic difficulty of robot handling. This proposition is in line with the idea that men pay more attention to specific elements (characteristic attributes of the robot) while women are processors of the relationships between all elements (of the robot with the environment) [65]. With these precedents, in the case of entertainment robots we can expect:

H7. For women, perceived ease of use will be a less important precedent of intention to use the robot than for men.

On the other hand, since men process information in a less exhaustive way and focus on specific elements, this procedure helps them establish quick relationships with less information [59] and, consequently, the perception that ease of use will be less relevant to their usefulness. Conversely, women, who see more complex relationships between the elements of the robot, will consider ease of use to be a more relevant factor for their usefulness. This has resulted in women's self-assessment as having less confidence in their performance with new technologies $[79,91]$ and considering 
that they have greater difficulty than men to understand them [82].

H8. For women, perceived ease of use will be a more important precedent of perceived usefulness than for men.

Regarding the hedonic precedent of HRI, Wang and Young [8] pointed out that men show greater enthusiasm for using robots for entertainment and, in addition, women tend to feel more nervous when interacting with robots, since, as noted above, they are more sensitive to any possible risk signals [86]. Some authors have also noted the greater propensity of men to agency and women to community, which drives men to look for new technologies in order to explore more personal interests, such as entertainment and economic performance, and women to seek greater social participation [8, 92]. However, as Canli et al. [66] pointed out, women showed a greater ability than men to store in memory and later recall entertainment experiences. Thus, in the case of entertainment robots:

H9. For women, perceived enjoyment will be a more important precedent of intention to use the robot than for men.

Studies on different motivational factors between the sexes show that women outperform men on socio-emotional, expressive and interpersonal traits, while men outperform women on task-oriented, instrumental and agentic traits [65]. In addition, differences in the influence of context on emotion expression have also been reported, i.e. women are more emotional in an interpersonal context, while men are more emotional in an achievement context [59]. In this study, both elements could be present: (1) men being emotional about achieving the goal of the game, and (2) women being emotional about engaging in an interpersonal conversation with the robot. However, the literature reports a greater tendency for women to be socially affiliated and to take others' opinions into account when making their own judgements $[8,59$, 93]. And, unlike men, they use new technologies more for social than for personal purposes. Women use the Internet with greater intensity than men to communicate with other people, for example, by sending emails [94]. In the case of entertainment robots, we propose:

H10. For women, perceived social influence will be a more important precedent of intention to use the robot than for men.

\subsection{Intuitive and Reflexive Processes}

Although the participant's reasoning system is a common variable in the literature on strategic management decisions [95], to our knowledge it has never been used in technology acceptance models of social robots. Nevertheless, it is not a variable that is entirely alien to the world of the new technologies, since it has been used to study the effect of use of smartphones [96]. According to the dual-process theory, when individuals must make a decision, they can tackle it through a fast heuristic process or through a more elaborate and slower analytical process [97, 98]. Although dual-process theories began to develop in the 1970s [99], it was not until the last decade that they have reached greater diffusion in the literature, probably due to the further development of evolutionary psychology [97, 98], the impact achieved by some of its applications [36] and their use in the study of strategic decisions [36, 95].

This theory proposes that individuals use two different evolutionary cognitive systems to process information: a primeval system, similar to that used by the more developed animals, and another that is unique to humans and superior to that of animals [98]. The first, considered primitive, autonomous, intuitive and which does not require memory work, is called system 1 and the second, deliberative, analytical, reflective, which requires memory work, cognitive decoupling and mental simulation, is called system 2 [34-36]. System 1, which is intuitive, is conceptualised as a rapid, non-conscious decision-making mechanism that uses patterns and associations of ideas to derive affective judgements [100]. As individuals who use heuristics to make their decisions, they later find it difficult to reconstruct and explain thoroughly the decision-making process [34]. In contrast, in system 2 , individuals use an analytical, systematic, rulebased and explicit mechanism to make decisions [101]. That is, they follow a step-by-step process that includes identifying and formulating the problem, thoroughly evaluating relevant information, generating a set of alternatives, evaluating them, and finally making a logical decision based on conscious deliberation $[34,95]$.

Although system 1 (intuitive) and system 2 (rational) are recognised as valuable for decision-making, they are fundamentally different $[97,98]$. It seems that people tend to use intuitive processes more frequently than cognitive decoupling, that is, more heuristic than abstract reasoning and cognitive reflection [102]. In an attempt to explain this bias, Todd [103] proposed that human beings, like all other living beings, have adopted the principle of energy efficiency in their behaviour. Because analytical processes require effort and consumption of energy resources, individuals generally try to avoid them by replacing them with quick and economical heuristics. This process has led to qualify human beings as miserly cognitive [35].

However, the use of quick heuristics does not mean making incorrect decisions. An evolutionary heuristic has been formed over thousands of years as a result of overcoming challenges to survival and, in many situations, can improve decision-making performance [104] and overcome more complex decisions [105]. Yet, some evidence shows that when individuals trust in their intuitive response, they are unlikely to rethink or change their decisions after reflection [106]. Furthermore, heuristic effectiveness depends on the environment. While in routine environments, where people 
have learned to identify the key elements, the use of system 1 can generate acceptable responses, whereas in hostile or stochastic ones, the responses of system 2 are more efficient [34].

Not all people exhibit the same behaviour, however, and some are less miserly and make more intense use of rationality than others [107]. In a study on the use of new technologies, it was found that smartphones were considered more useful and practical by the more miserly cognitive than by those with a greater propensity to rationality [96]. That is, those who rely more on intuition are more prone to intensive use of smartphones, since they resort to their smartphone more than to their mind to obtain information, thereby showing a greater dependence on that external source than people who use their own mental resources [106]. In other words, the principle of energy efficiency still applies [103] and users are getting used to having a portable brain and not consuming energy from their own. We expect these individuals to adopt the same logic with social robots and, by accepting an entertainment robot, we can propose the following hypothesis:

H11. For participants using heuristics (system 1), perceived usefulness will be a more important precedent for the intention to use the robot than for participants using reasoning (system 2).

As noted above, people with system 1 (heuristic) resort to looking for key elements that facilitate their assessment. That is, among all the variables that can affect decision-making, they only focus on a few that they consider relevant (for example, if a consumer is considering the purchase of a product, $\mathrm{s} /$ he must use price or brand as a heuristic criterion). But, when these elements are difficult to assess, they are often replaced by easier ones, even if they are less accurate [107]. This implies that for a consumer applying heuristic logic there is no real perception of difficulty [34], since, to continue with the example, if the consumer is unfamiliar with the brand, s/he simply resorts to price as a decision criterion. Therefore, for participants who use heuristic logic in their decision process, ease of use will not be relevant for them. In the case of entertainment robots, we hope this predisposition also prevails:

H12. For participants using heuristics (system 1), perceived ease of use will be a less important precedent for the intention to use the robot than for participants using reasoning (system 2).

However, the principle of energy efficiency that prevails in participants applying system 1 [103] will cause them to consider ease of use as a precedent for determining the usefulness of the robot. Something similar has been detected with the use of smartphones, since their greater use among the miserly cognitive is closely related to proximity, accessibility and ease of use [96]. With these precedents, in the case of entertainment robots we can expect:
H13. For participants using heuristics (system 1), perceived ease of use will be a more important precedent of perceived usefulness than for participants using reasoning (system 2).

It is difficult to establish a relationship between cognitive systems and entertainment perception. Studies that have analysed entertainment have traditionally focused on the measure of hedonic and pleasurable responses [108]. However, Oliver and Bartsch [109] considered that from the feeling of enjoyment two different qualitative experiences must be distinguished: mere enjoyment and appreciation. Thus, while enjoyment generates immediate positive responses of excitement and enthusiasm, appreciation generates more reflective and long-lasting cognitive responses [109]. Similarly, Vorderer and Ritterfeld [110] discussed the distinction between enjoyment and appreciation in the context of digital games, considering that, in contrast to entertainment games, experiencing appreciation was more related to educational games (called serious games) that allow for higher-order goals, such as improving competence [110].

Lewis et al. [111] associated these experiences derived from enjoyment with the dual-process theories. They proposed that while enjoyment follows a quick and intuitive process to generate a response, appreciation, in contrast, requires a slow and controlled evaluation, capable of weighing up the existence of conflicting needs or emotions [111]. Although this distinction has not been made in this study, the context in which the study is framed means that we consider perceived enjoyment in an HRI to be closer to appreciation than mere enjoyment. Therefore, given that appreciation requires analytical effort and the consumption of energy resources, people who are more predisposed to the use of heuristics (system 1) will try to avoid their involvement and will therefore value this driver less when accepting this new technology [35]. This consideration is in line with findings obtained by Barr et al. [96] in their experiments. Although they have not been able to find significant relationships, their results pointed towards a greater predisposition to entertainment with the use of smartphones by more rational users. In this study we want to determine whether this indication can be verified in the case of entertainment robots.

H14. For participants using heuristics (system 1), perceived enjoyment will be a less important precedent for the intention to use the robot than for participants using reasoning (system 2).

Something similar occurs between the social influence and the cognitive system of individuals. Although we have not found any direct evidence, the work by Pennycook and Rand [35] suggests that individuals who follow system 1 show greater credulity regarding epistemically suspicious information (fake news), greater religious belief and, conversely, a greater disbelief towards scientific proposals, such as evolution, than those who follow a deliberative reasoning process 
Table 1 Demographic profile of the respondents

\begin{tabular}{llll}
\hline Variable & Description & Frequency & Percentage \\
\hline Gender & Male & 113 & 51.6 \\
& Female & 106 & 48.4 \\
Age & 18-24 years & 42 & 19.2 \\
& 25-34 years & 66 & 30.1 \\
& 35-44 years & 43 & 19.6 \\
& 45-54 years & 41 & 18.7 \\
Nationality & More than 54 years & 27 & 12.4 \\
& Spanish & 183 & 83.6 \\
& Rest of Europe & 13 & 5.9 \\
& North American & 2 & 1 \\
& South American & 11 & 5 \\
& Asian & 4 & 1.8 \\
& Others & 6 & 2.7 \\
\hline
\end{tabular}

[36]. That is, all these studies underline a greater independence on opinion among people who use reasoning rather than intuition and, therefore, a lesser need for social approval to make their decisions. Other evidence has shown that more intuitive users make more intensive use of smartphones and social networks than those who show greater intensity ability [96]. Associating this idea with the acceptance of an entertainment robot, we can propose that:

H15. For participants using heuristics (system 1), perceived social influence will be a more important precedent for the intention to use the robot than for participants using reasoning (system 2).

\section{Research Method}

Data were collected from 219 participants $(51.6 \%$ men) between 18 and 67 years of age and, mostly, Spanish (see details in Table 1). The sample was collected among thousands of visitors who, during a weekend, attended a fair on ecological, intelligent and sustainable products in the city of Barcelona. To carry out the field work, we installed a stand consisting of two adjacent spaces and, to encourage participation, we invited visitors to take part in a game with a TIAGo robot.

TIAGo is a semi-humanoid robot whose physiognomy is made up of a head, a torso, an integrated arm and a base for its displacement. It has a wrist sensor, a processor, RAM and SDD memory, and laser navigation [112]. In addition, it has skills in perception, navigation, manipulation and interaction with people, since it has an integrated system with Artificial Intelligence algorithms. Furthermore, it also has an LCD screen in its head that reproduces, in the form of an animated cartoon, facial expressions in coordination with

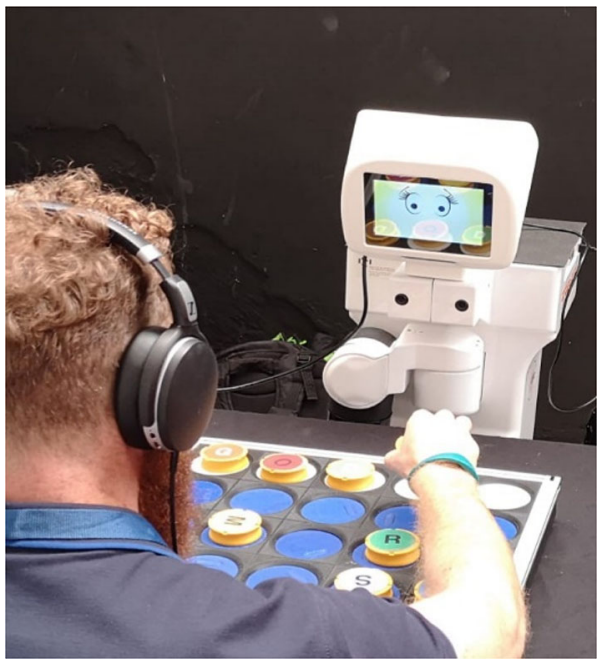

Fig. 1 Participant playing the game with the assistance of the robot

the conversation [39]. All these skills and equipment make TIAGo a versatile social robot, capable of following a conversation and adapting to the degree of help the participant needs (Fig. 1 show photo playing with TIAGo).

The goal of inviting participants to play a game with a TIAGo robot was to offer them a first-hand experience, as recommended by Suchman [28] and Savela et al. [51]. The word-game consisted in guessing the five-letter name of a Nobel Prize winner using the ten letters available on the board. The moment the participant sat in front of the board and the TIAGo, the robot greeted her/him and explained how to play; during the game it offered different verbal clues, depending on the user's ability to complete it. After this experience, participants answered a questionnaire evaluating 19 statements that form the five constructs analysed with a 5-point Likert scale ranging from (1) totally disagree to (5) totally agree. "Appendix A" presents the constructs, their items and the source from which they were adapted. Finally, respondents completed identification data and seven items of the two versions of the Cognitive Reflection Test (CRT). The CRT is a scale consisting of open questions that have the characteristic of intuiting a simple but incorrect answer, the correct answer being something more complex and difficult to discover. It has been used in the literature to estimate the prevalence of the cognitive system and, in this study, the seven-item version (three numerical and four non-numerical) was used $[35,36]$. "Appendix B" shows the expressions. Both the general model and the models resulting from dividing the sample between sexes or between cognitive systems were estimated by SEM, from variance and covariance matrices according to maximum likelihood with EQS 6.4 [113]. As for the multigroup analysis, first, an invariance test was performed showing that the factor loadings of the two groups can be equalised, this was carried out for both multigroup analy- 
Table 2 Analysis of the dimensionality, reliability and validity of the scales (mean and $\mathrm{SD})$

\begin{tabular}{|c|c|c|c|c|}
\hline & Factor loading & $\mathrm{T}$ & Mean & SD \\
\hline \multicolumn{5}{|l|}{ Perceived enjoyment (AVE: 0.67; CR: 0.83; Alpha: 0.83) } \\
\hline It's fun to talk to the robot & 0.81 & 3.61 & 3.10 & 1.31 \\
\hline It's fun to play with the robot & 0.88 & 3.62 & 3.56 & 1.21 \\
\hline The robot looks enjoyable & 0.66 & 3.58 & 2.91 & 1.32 \\
\hline \multicolumn{5}{|l|}{ Perceived ease of use (AVE: $0.67 ; C R: 0.83$; Alpha: 0.82) } \\
\hline Immediately I learned how to use the robot & 0.83 & 4.83 & 3.93 & 1.14 \\
\hline The robot seemed easy to use & 0.81 & 4.47 & 4.10 & 1.06 \\
\hline I think I can use the robot without any help & 0.71 & 4.53 & 3.71 & 1.19 \\
\hline \multicolumn{5}{|l|}{ Perceived usefulness (AVE: 0.66; CR: 0.83; Alpha: 0.82) } \\
\hline I think the robot is useful to entertain & 0.68 & 6.97 & 3.87 & 1.24 \\
\hline It would be nice to have the robot to entertain & 0.85 & 7.96 & 3.09 & 1.25 \\
\hline I think the robot could be used to entertain me and do other things & 0.81 & 7.38 & 3.38 & 1.21 \\
\hline \multicolumn{5}{|l|}{ Social influence (AVE: 0.70; CR: 0.85; Alpha: 0.84) } \\
\hline I think my friends would like me to use the robot & 0.74 & 11.96 & 2.96 & 1.20 \\
\hline I think it would give a good impression if I played with the robot & 0.90 & 20.83 & 2.90 & 1.19 \\
\hline $\begin{array}{l}\text { People whom I value your opinion I think they would look good } \\
\text { that I play with the robot }\end{array}$ & 0.78 & 15.63 & 3.12 & 1.22 \\
\hline \multicolumn{5}{|l|}{ Intention to use (AVE: 0.67; CR: 0.83; Alpha: 0.82) } \\
\hline If the robot was available I would try to use it & 0.71 & 3.52 & 3.37 & 1.15 \\
\hline $\begin{array}{l}\text { If the robot was available I would try to use it whenever I could in } \\
\text { my spare time }\end{array}$ & 0.88 & 3.70 & 2.74 & 1.22 \\
\hline $\begin{array}{l}\text { If the robot was available I would be thinking sometimes when } \\
\text { using it }\end{array}$ & 0.77 & 3.55 & 2.18 & 1.15 \\
\hline
\end{tabular}

The model fits Chi-square $\left(\chi^{2}\right): 82.6673 ; d f: 74 ; p$ : 0.22943; RMSEA: 0.023; CFI: 0.995; NNFI: 0.992 $A V E$ is the average variance extracted, $C R$ is the composite reliability ses (gender and cognitive system). The two groups were then analysed simultaneously. Finally, the relations were equated 1 to 1 , allowing significant differences to be determined through variation of the chi-square statistic, when comparing the constrained and unconstrained model [113].

\section{Analysis and Results}

Before analysing the model, the psychometric characteristics of the scales were studied, which resulted in the removal of four items. Table 2 describes the dimensionality, reliability and validity of the resized scales and Table 3 shows their discriminant validity. Cronbach's alpha coefficient was calculated to estimate the reliability of latent variables. Results confirmed that all coefficients were above 0.7 (the cut-off point recommended by the literature) [114]. A relationship model based on UTAUT was then estimated using SEM, which calculates the effect that different constructs have on the dependent variable and, in addition, the amount of variability explained by this relationship model $\left(R^{2}\right)$. The $R^{2}$ generated were in line with the sample size used: an $R^{2}$ of 0.90 for the intention to use as the dependent variable and
0.11 for the perceived usefulness (Table 4, and Fig. 2 shows the results as a path diagram).

The five hypotheses of the general model were confirmed. According to the findings obtained, the intention to use an entertainment robot is mainly explained by the social influence $(0.45)$ and by the perceived enjoyment $(0.31)$, a little less by the perceived usefulness $(0.25)$, and ease of use (0.12) was the one that reached the lowest significant value. A rather surprising result is that the main argument for using the social robot was social influence, bearing in mind that the robot's goal is to entertainment. In turn, perceived usefulness was explained by perceived ease of use (0.33).

Next, the sample was divided by sex (biological criterion), between men and women, and a model for each segment was estimated using SEM. Although the $R^{2}$ are in line with the size of the subsamples, the women's segment generated models with greater variability explained. For example, in the intention to use an entertainment robot, the $R^{2}$ of women was 0.81 , while in men it had a value of 0.77 (Table 5, and Fig. 3 shows the results in a path diagram).

All five proposed hypotheses on sex differences have been confirmed. That is, H6 suggested that perceived usefulness is a more important precedent among men (0.37) than among women $(0.06$, n.s.), H7 hypothesised that perceived ease of 
Table 3 Discriminant validity of the scales

\begin{tabular}{|c|c|c|c|c|c|}
\hline & Enjoyment & Ease of use & Usefulness & Social influence & Intention to use \\
\hline Enjoyment & 0.82 & & & & \\
\hline Ease of use & $0.40 * * *$ & 0.82 & & & \\
\hline Usefulness & $0.62 * *$ & $0.35^{* * *}$ & 0.81 & & \\
\hline Social influence & $0.67 * * *$ & $0.11(\mathrm{~ns})$ & $0.67 * * *$ & 0.83 & \\
\hline Intention to use & $0.64 * * *$ & $0.11(\mathrm{~ns})$ & $0.61 * * *$ & $0.64 * * *$ & 0.82 \\
\hline
\end{tabular}

Below the diagonal: correlation estimated between the factors

Diagonal: square root of AVE

$* \mathrm{p}<0.05 ; * * \mathrm{p}<0.01 ; * * \mathrm{p}<0.001$

Table 4 Causal relations in the general model

\begin{tabular}{lllll}
\hline Independent variable & Dependent variable & Beta & T & R2 \\
\hline PU & ITU & 0.25 & 2.05 & 0.90 \\
PEOU & & 0.12 & 2.21 & \\
PENJ & & 0.31 & 4.73 & \\
SI & & 0.45 & 4.23 & \\
PEOU & PU & 0.33 & 3.63 & 0.11 \\
\hline
\end{tabular}

Significant at $\mathrm{p}<0.05$

ITU, intention to use; PU, perceived usefulness; PEOU, perceived ease of use; PENJ, perceived enjoyment; SI, social influence use is a less important precedent of intention to use for women $(0.05$, n.s.) than for men $(0.28), \mathrm{H} 9$ proposed that for women, perceived enjoyment is a more important precedent of intention to use the robot $(0.42)$ than for men $(0.15)$, and $\mathrm{H} 10$ posited that perceived social influence is a less important precedent for the intention of use among men (0.33) than among women (0.58), all of them with significant differences. In addition, $\mathrm{H} 8$ proposed that perceived ease of use is a less important precedent for perceived usefulness among men (0.29) than women (0.39), with significant differences.

Finally, the correct CRT responses made by participants were quantified, the median was estimated and the sample was divided into two subgroups. These responses were
Fig. 2 General structural model results $(\mathrm{p}<0.05)$

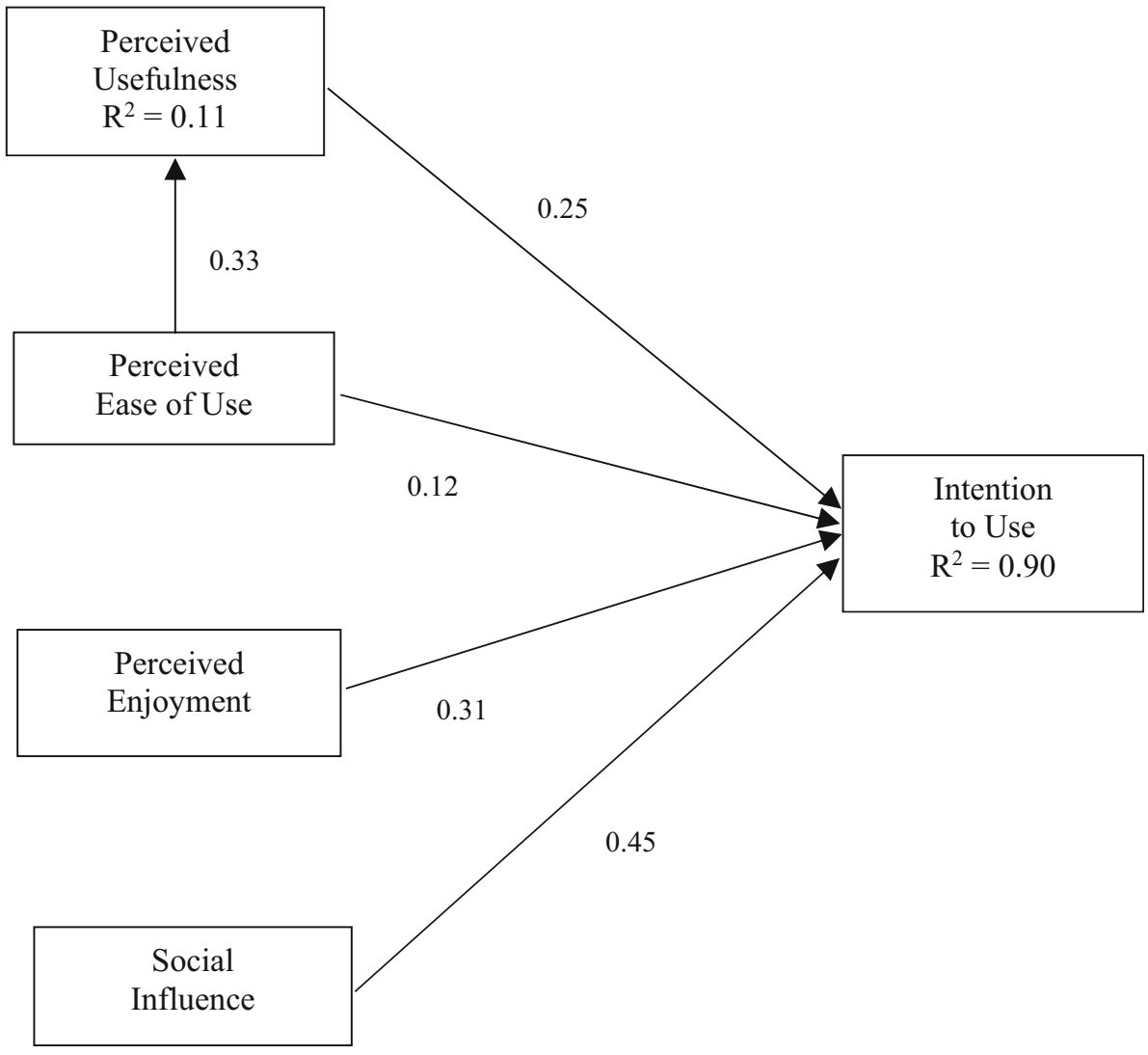


Fig. 3 Structural model results. Causal relationships for men and women $(\mathrm{p}<0.05)$

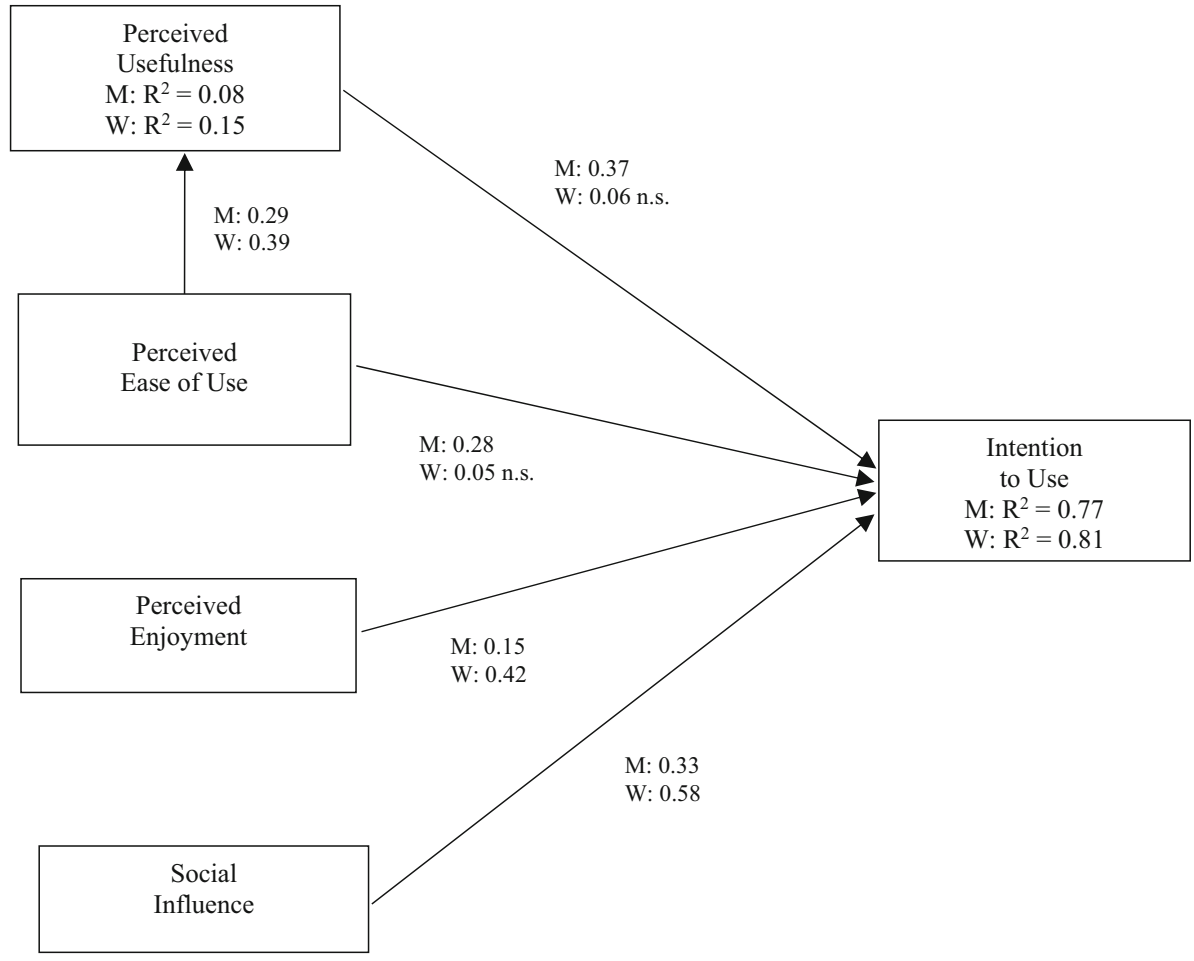

used as an estimator of the cognitive process followed by respondents $[35,36]$ and system 1 was assigned to those who followed a more intuitive or heuristic process (obtaining three or fewer correct answers) and system 2 to those who followed a more rational process (obtaining more than three correct answers). Models for each subsample were estimated using SEM. Regarding the $R^{2}$ values, in this study the explanatory capacity of rational approaches in the intention to use an entertainment robot were greater than those of gender, the rational segment (system 2) models obtaining greater variability explained $\left(R^{2}=0.92\right)$ than the heuristics $\left(R^{2}=\right.$ $0.85)$. However, the results of these two models do not show many more significant differences among the precedents of the intention to use a social robot than the sex-adjusted models (Fig. 4 shows the results in a path diagram).

Of the last five hypotheses proposed, only two have been confirmed (H12, H15). According to H12, perceived ease of use is a less important predictor among participants who adopt system 1 (0.05 n.s.) than among those who use system 2 (0.25), and H15, social influence is a more important precedent among participants who adopt system $1(0.50)$ than among those relying on system 2 (0.36), both with significant differences. Regarding the rest of the hypotheses, H11, which proposed that the perceived usefulness is a more important precedent among participants who adopt system $1(0.26)$ than among those with system $2(0.20)$, differences were not significant and the hypothesis was not confirmed. In the case of $\mathrm{H} 13$, perceived usefulness is explained a little more by perceived ease of use by those of system 2 (0.38) than those of system 1 (0.32), against expectations but without significant differences. For the proposal of H14 that perceived enjoyment is a less important precedent among system $1(0.28)$ than among system $2(0.34)$, although the values point in the expected direction, the differences were not significant.

\section{Discussion and Conclusions}

This study proposes that parsimonious adaptation of the UTAUT model can be used to evaluate the technological acceptance of different social robot appliances [17, 18]. In this study, the acceptability of a social robot equipped to entertain, assist and provide companionship has been evaluated after a real-life HRI experience. Furthermore, it proposes that market segmentation criteria should be taken into account to analyse their acceptance. Specifically, in accordance with the classification put forward by Nomura [11], we study the acceptance of the social robot according to sex and also the moderating role that can be played by the users' cognitive system. The results offer practical ideas for robotic equipment designers to deliver designs that are more likely to be accepted by different market segments.

On the one hand, the adapted UTAUT model explains $90 \%$ of the variability, providing a better fit than those achieved by more complex models, such as the Almere model of Heerink et al. (2010) [23] or the RAM-care model of Turja et al. [24]. Moreover, it is more suitable than the TAM for evaluating services as it considers factors of the three essential 
Fig. 4 Structural model results. Causal relationships for system 1 (intuitive) and system 2 (reflexive) $(\mathrm{p}<0.05)$

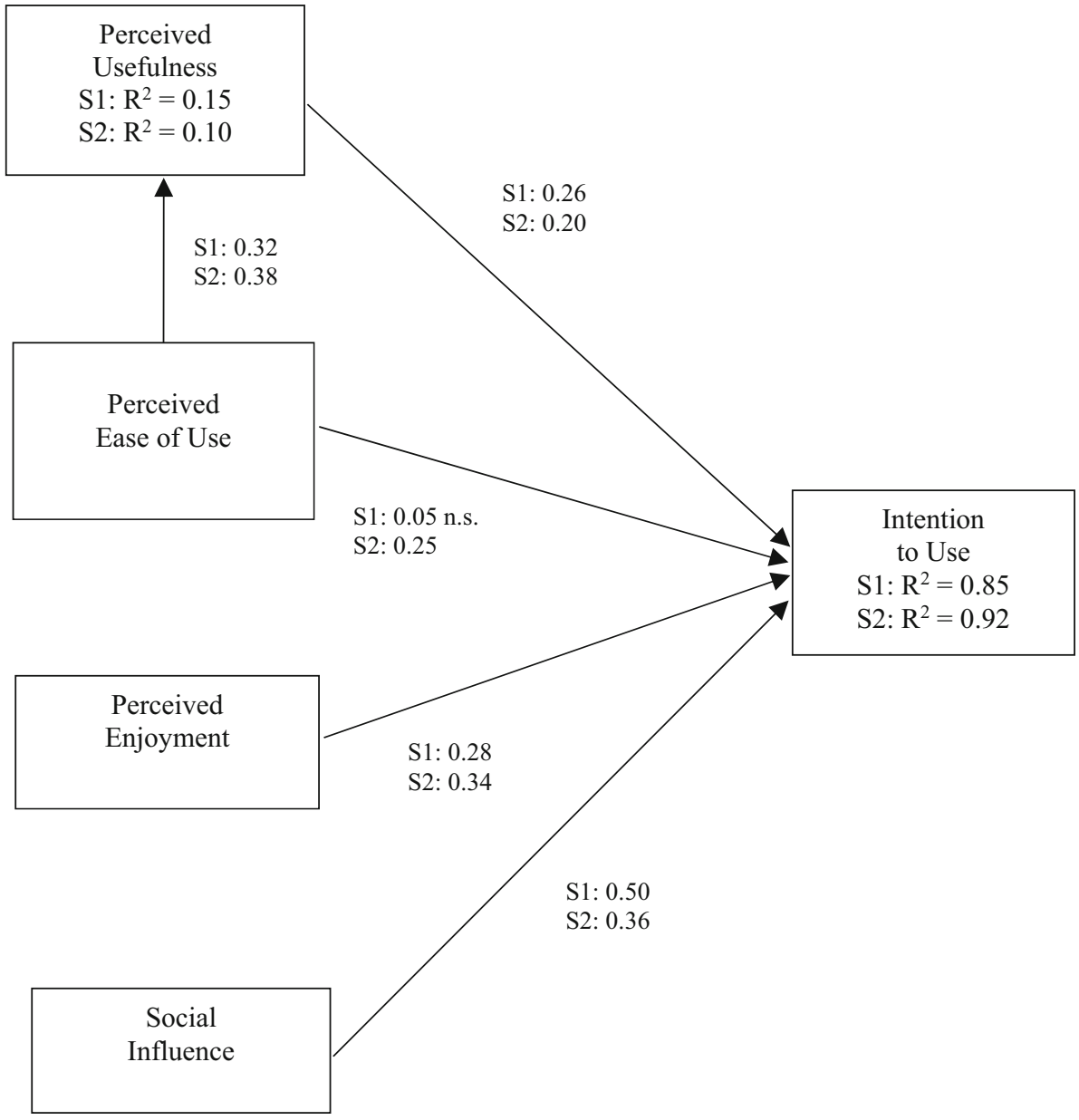

elements that make up the experience, i.e. cognitive, affective and behavioural factors [43]. On the other hand, this model is easily applicable by any practitioner, even if not proficient in SEM, as fitting it with OLS produces very similar results [115].

The findings of the full model indicate that the main drivers of intention to use are, in order of importance, social influence (affective factor), hedonistic motives (behavioural factor), perceived usefulness and perceived ease of use (both cognitive factors). In other words, the results point to a predominance of socio-emotional and relational functions over utilitarian and functional ones, which are common in the delivery of services [55]. Undoubtedly, the fact that the study has been approached from the consumer's perspective rather than that of practitioners (i.e. Turja et al. [24]) may explain this shift towards more affective and behavioural factors. Next, we ask whether the factors that directly influence the intention to use social robots will differ by market segment, that is, between men and women or between more heuristic and rational users. The results are discussed in the following.

First, the results support a positive relationship between perceived usefulness and the intention to use a social robot in four of the five models analysed. Although it has a belowaverage weight in the full model, consumers consider that a social robot should also fulfil utilitarian and not merely protocol functions. These results are consistent with those previously obtained with other technologies $[17,116]$, as well as with social robots $[23,24]$. However, by segment, when users are divided by sex, the results, in line with Brunel and Nelson [88] and Multu et al. [89], point to a preference for instrumentality and utility in men, but not in women, since this relationship does not obtain significant results. That is, men's different ability to focus their attention on the relevant elements of social robots makes them appreciate their instrumentality and usefulness, while women, who tend to process information in a more holistic way, do not see any practical utility in the context experienced [87-89]. On the other hand, when the analysis is performed comparing by cognitive system, based on the principle of energy efficiency (103), the more heuristic tend to give greater importance to the useful and practical elements of new technologies than the more rational, who usually consider themselves selfsufficient [96]. Although the results point in that direction, 
in agreement with those reported by Barr et al. [96], they do not reach significant differences.

Second, although in the overall model these results predict a positive relationship between perceived ease of use and intention to use a social robot, it was the least significant driver. However, it reached a higher and significant value for the male model and the more rational user model. Ease of use is a controversial factor that, despite the high incidence in studies on the adoption of new technologies [17, 116, 117], was not significant in the study with social robots by Turja et al. [24] and, consistent with the results of this study, had only a small impact in the work of Heerink et al. [23]. We believe that these results respond more to a lack of knowledge about the robot's functions than a consideration of how difficult it may be to operate it. In terms of sex segmentation, contrary to Croson and Gneezy [91] and Vorvoreanu et al. [79], ease of use is a significant argument to explain the intention to use only in men, with no significant result in women. This result is consistent with the findings on perceived usefulness and in consonance with the idea that men pay more attention to specific elements than women. This characteristic feature allows men to establish relationships between objects [90] and to perceive the difficulty of handling them more quickly than women, who process the relationships between all items in a broad way [65]. Furthermore, these results are in agreement with the greater predisposition of men to evaluate tasks and functions compared to women, who assign greater importance to interactions $[8,89]$. Regarding the cognitive system, the results also go in the opposite direction to what Toplak et al. [107] indicated, although in line with what was hypothesised, since the ease of use is only explained for rational users, as heuristics have no real perception of the difficulty of using a social robot [34].

Third, given that the robot was equipped with software enabling it to provide both assistance and entertainment, the results point to a positive relationship between perceived enjoyment and intention to use. Perceived enjoyment is one of the most influential factors in the technological acceptance of almost all models. These findings are in agreement with those of Turja et al. [24], who found that perceived enjoyment is the main factor explaining practitioners' intention to use care robots, and contrary to those obtained by Heerink et al. [23], where utilitarian factors predominate over hedonics with samples of elderly persons. These contradictory outcomes could be explained both by using diverse target audiences and by assessing different experiences. Thus, while Heerink et al. [23] used elderly people rating a Wizard-of-Oz scenario, Turja et al. [24] asked professional caregivers, mostly nurses, with experience in using robots such as Nao or Paro Seal and therefore greater knowledge of their limited functions [28]. In other words, it seems that a greater knowledge of the real abilities of robots makes them value hedonic factors more than utilitarian ones. Comparing the sexes yields one of the most interesting results. For women, unlike men, the entertainment function is one of the most important drivers for accepting social robots. This result suggests that for women the robot's ability to entertain, amuse or distract is central to their acceptance and this idea links with Canli et al. [66], who pointed out that women remember entertaining experiences better than men. The hypothesis is confirmed, but contradicts the results obtained by Wang and Young [8] and Hupfer and Detlor [92]. For Wang and Young [8], men perceive entertainment robots and their potential impact more positively than women. Regarding the cognitive system, Oliver and Bartsch [109] differentiated between mere enjoyment and appreciation. Given that the game under consideration requires a cognitive effort and that appreciation is more related to educational games than to purely hedonic ones, we have considered the first meaning, i.e. appreciation. However, although the results point to those obtained by Barr et al. [96], giving greater importance to entertainment by people following system 2 than those following system 1, these differences are not significant.

Fourth, the findings back a positive relationship between social influence and intention to use across all five models. The belief about how peers and family members would view me using the robot has a great influence on its acceptance. These results are consistent with the findings of previous UTAUT-based studies $[17,116]$ and, in the case of social robots, the values reached in our study are much higher than those of Heerink et al. [23] and Turja et al. [24]. According to the sex segmentation criterion, unlike males, for females, social influence is the most valued factor. The results fit the prediction, as women are more emotional in an interpersonal context (conversation with the robot), while men are more emotional in an achievement context (getting the right answer) [59]. We believe that in this study both emotional elements may have affected the weight achieved by the driver of social influence. However, the literature reports a greater tendency for women to be more socially affiliated and to take others' opinions more into account when making their own judgements $[8,93,94]$. In terms of the cognitive system, we detected a significant difference in perceived social influence on intention to use, which was greater among heurists than among rationals. As noted above, indirect evidence points to greater credulity and trust in the opinion of others on the part of system 1 followers than more rational followers [36]. That is, there tends to be greater independence of opinion among system 2 users than among heuristics, who also need less social approval to make their decisions.

Fifth, the results also predict a positive relationship between perceived ease of use and perceived usefulness across all five models. These findings are consistent with those obtained in previous studies with UTAUT models [116, 118] or with Heerink et al. [23] with social robots. Regarding sex segmentation, women find the relationship between 
Table 5 Causal relations in men/women and intuitive/reflexive

\begin{tabular}{lllllllllllllllll}
\hline $\begin{array}{l}\text { Independent } \\
\text { variable }\end{array}$ & $\begin{array}{l}\text { Dependent } \\
\text { variable }\end{array}$ & $\begin{array}{l}\text { Men } \\
\text { Beta }\end{array}$ & T & R2 & $\begin{array}{l}\text { Women } \\
\text { Beta }\end{array}$ & T & R2 & P & $\begin{array}{l}\text { System 1 } \\
\text { intuitive } \\
\text { Beta }\end{array}$ & T & R2 & $\begin{array}{l}\text { System 2 } \\
\text { Reflexive } \\
\text { Beta }\end{array}$ & $\begin{array}{c}\text { T } \\
\text { R2 }\end{array}$ & P \\
\hline PU & ITU & 0.37 & 2.10 & 0.77 & $0.06^{*}$ & 0.37 & 0.81 & 0.03 & 0.26 & 1.99 & 0.85 & 0.20 & 2.05 & 0.92 & 0.86 \\
PEOU & & 0.28 & 3.50 & & $0.05^{*}$ & 0.85 & & 0.04 & $0.05^{*}$ & 0.85 & 0.25 & 2.53 & 0.02 \\
PENJ & & 0.15 & 2.09 & & 0.42 & 3.82 & & 0.04 & 0.28 & 3.58 & 0.34 & 3.50 & 0.18 \\
SI & & 0.33 & 2.58 & & 0.58 & 4.04 & & 0.03 & 0.50 & 3.64 & 0.36 & 2.57 & 0.03 \\
PEOU & PU & 0.29 & 2.32 & 0.08 & 0.39 & 2.93 & 0.15 & 0.02 & 0.32 & 3.09 & 0.15 & 0.38 & 2.20 & 0.10 & 0.80 \\
\hline
\end{tabular}

Significant at $\mathrm{p}<0.05$

*Not significant

easy and useful more positive than men. On the one hand, this result indicates that women recognise the complexity involved in linking the elements of the robot and value ease of use as a relevant factor in considering its usefulness. On the other hand, it also highlights the fact that women have less confidence in the performance and understanding of new technologies than men [82]. By cognitive system, more rational users, who tend to follow a step-by-step analysis process, are more able to relate ease of use to usefulness and rate it slightly more positively than those assigned to the heuristic segment, although the differences are not significant. However, as this is an indirect effect, its impact on intention to use is very small.

While it is undeniable that new technologies, as well as robotic equipment, provide services that enable convenient and accessible interactions, some authors have criticised that this is at the expense of the emotional and human side of service delivery $[24,55]$. This study proposes to advance service delivery with social robots with the capacity to perform entertainment activities and capable of conveying feelings and emotions.

With the degree of development reached by the most common social robots available on the market, such as TEMI, JAMES, Pepper, etc. [119], the evidence collected in this study suggests that social influence and hedonistic motives predominate over utilitarian ones in the intention to use social robots in an entertainment context. However, by segment, men prefer a robot that is balanced between functionality and sociability, while women give more importance to sociability and entertainment factors. Evidence on the effect of context has also been published in the literature [120]. Thus, Schermerhorn, Scheutz and Crowell [121], who studied the effect of the presence of a robot during a human activity, found that men tend to regard robots as more "human" and are more accepting of HRI than women. In this study, however, where there was direct interaction, it was women who were somewhat more accepting of HRI. Overall, existing research suggests that artificial entities interact with context and human sex in complex ways that cannot be reduced to a few simple dimensions or explanations [120, 122]. As for the cognitive segments, for the more heuristic individuals, social influence is the most relevant factor, while the more rational ones prefer robots that are more balanced between sociability and entertainment.

\section{Implications and Limitations}

Although a significant number of social robots, such as TEMI, JAMES, Pepper, iCat, PARO Seal and Nao, among others, have already been implemented in health centres to entertain and provide patients with companionship [23, 24, 119], the most advanced humanoid robots such as TIAGo are still in the lab phase and it is difficult to predict their evolution [39]. However, the findings of this study suggest that an entertainment robot should offer not only functional but also socio-emotional and relational outcomes [54] in order to achieve a positive experience and greater technological acceptance [55]. In addition, users do not see the utilitarian functions as very practical and so, to compensate, designers should develop more hedonic and relational functions in order to achieve greater acceptance.

Some implications stem from these results. First, as a theoretical contribution, a parsimonious adaptation of the UTAUT model is proposed to study the technological acceptance of a social robot equipped to perform entertainment activities considering four factors and two moderators: sex (common in UTAUT) and the cognitive system, which is the main novelty of this study. Second, as an academic contribution, the theoretical relationships underpinning sex differences are presented. The extreme poles are described: nativists, who consider genetic-biological inheritance as the basis for different behaviour, and environmentalists, who attribute it to the socio-cultural context [56, 63]. Moreover, more recent contributions from neuroscientific studies do not seem to contribute to alleviating the disparate positions [64]. This study aims to maintain an eclectic position and is framed as an inclusive approach where robots' designers can accept that women and men may have different needs and preferences, but should aim for an inclusive and enabling solution [8]. Third, a less controversial criterion, although with a strong substratum of evolutionary psychology, is the differ- 
ence between cognitive systems (system 1 vs. system 2). This is one of the main novelties of this study and, although it does not show as many differences as sex, some are of transcendental importance, as is the case of the different weight of social influence between heuristics and rationales, for example. Finally, although many studies use Wizard-of-Oz settings or video images to study HRI, this study advocates using real robots to make participants fully aware of their real abilities and to avoid disappointment [28, 51].

Findings gathered in this research should be taken with caution, since all participants experienced for the first time an interaction with a semi-humanoid social robot, so the technological acceptance model and the intention to use are very hypothetical [123]. We hope that as users increase their familiarity with social robots, their perspective and the factors considered relevant to the intention to use will change. Another limitation has been the use of a convenience sample. As it was extracted from visitors to the fair who agreed to collaborate in the research, this makes no statistical inference possible. Although we have attempted to find a balance between men and women, the age of participants has not been controlled for. Among possible extensions, we believe that it might be interesting to continue carrying out studies of technological acceptance using the cognitive approach and focusing on the gender of subjects. Since gender is the factor that has generated the most interesting results, its interaction with other personality or characteristic traits could be proposed as a promising line of future research.

Funding Open Access funding provided thanks to the CRUE-CSIC agreement with Springer Nature. This work has been partially funded by the EU Project SOCRATES H2020-MSCA-ITN-721619, by the European Union's Horizon 2020 under ERC Advanced Grant CLOTHILDE (No. 741930), by the Spanish Ministry of Science and Innovation HuMoUR TIN2017-90086-R, and by the State Research Agency through the María de Maeztu Seal of Excellence to IRI (MDM-20160656).

Data availability The datasets generated during and/or analysed during the current study are available from the corresponding author on reasonable request.

\section{Declarations}

Conflict of interest The authors declare that they have no conflict of interest.

Ethical Standard All participants were healthy adults who were informed that if at any point they did not wish to continue with the study, they could withdraw from the experiment. The study was approved by the Ethical Committee of the Spanish National Research Council (reference code 056/2019).

Informed Consent Informed consent was obtained from all individual participants included in the study.
Open Access This article is licensed under a Creative Commons Attribution 4.0 International License, which permits use, sharing, adaptation, distribution and reproduction in any medium or format, as long as you give appropriate credit to the original author(s) and the source, provide a link to the Creative Commons licence, and indicate if changes were made. The images or other third party material in this article are included in the article's Creative Commons licence, unless indicated otherwise in a credit line to the material. If material is not included in the article's Creative Commons licence and your intended use is not permitted by statutory regulation or exceeds the permitted use, you will need to obtain permission directly from the copyright holder. To view a copy of this licence, visit http://creativecomm ons.org/licenses/by/4.0/.

\section{Appendix A}

Constructs and items used

\begin{tabular}{|c|c|c|c|}
\hline Code & Construct & Items & Adapted from \\
\hline \multirow[t]{2}{*}{ ITU } & \multirow[t]{2}{*}{ Intention to use } & $\begin{array}{l}\text { If the robot was } \\
\text { available, I } \\
\text { would try to } \\
\text { use it }\end{array}$ & $\begin{array}{l}\text { Palau-Saumell, } \\
\text { R., } \\
\text { Forgas-Coll, S., } \\
\text { Sánchez- } \\
\text { García, J., } \\
\text { Robres, E. } \\
\text { (2019) }\end{array}$ \\
\hline & & $\begin{array}{l}\text { If the robot was } \\
\text { available, I } \\
\text { would try to } \\
\text { use it whenever } \\
\text { I could in my } \\
\text { spare time } \\
\text { If the robot was } \\
\text { available, I } \\
\text { would } \\
\text { sometimes } \\
\text { think about } \\
\text { using it }\end{array}$ & \\
\hline \multirow[t]{3}{*}{ PU } & \multirow[t]{3}{*}{$\begin{array}{l}\text { Perceived } \\
\text { Usefulness }\end{array}$} & $\begin{array}{l}\text { I think the robot } \\
\text { is useful to } \\
\text { entertain }\end{array}$ & $\begin{array}{l}\text { Heerink, M., } \\
\text { Kröse, B., } \\
\text { Evers, V. } \\
(2010)\end{array}$ \\
\hline & & $\begin{array}{l}\text { It would be nice } \\
\text { to have the } \\
\text { robot to } \\
\text { entertain }\end{array}$ & \\
\hline & & $\begin{array}{l}\text { I think the robot } \\
\text { could be used } \\
\text { to entertain me } \\
\text { and do other } \\
\text { things }\end{array}$ & \\
\hline \multirow[t]{2}{*}{ PEOU } & \multirow[t]{2}{*}{$\begin{array}{l}\text { Perceived Ease } \\
\text { of Use }\end{array}$} & $\begin{array}{l}\text { I immediately } \\
\text { learned how to } \\
\text { use the robot }\end{array}$ & \\
\hline & & $\begin{array}{l}\text { The robot } \\
\text { seemed easy to } \\
\text { use }\end{array}$ & \\
\hline
\end{tabular}




\begin{tabular}{|c|c|c|c|}
\hline Code & Construct & Items & Adapted from \\
\hline & & $\begin{array}{l}\text { I think I can use } \\
\text { the robot } \\
\text { without any } \\
\text { help }\end{array}$ & \\
\hline & & $\begin{array}{l}\text { I think I can use } \\
\text { the robot with } \\
\text { someone's help }\end{array}$ & \\
\hline & & $\begin{array}{l}\text { I think I can use } \\
\text { the robot if I } \\
\text { have some } \\
\text { good } \\
\text { instructions }\end{array}$ & \\
\hline \multirow[t]{5}{*}{ PENJ } & $\begin{array}{l}\text { Perceived } \\
\text { Enjoyment }\end{array}$ & $\begin{array}{l}\text { It's fun to talk to } \\
\text { the robot }\end{array}$ & \\
\hline & & $\begin{array}{l}\text { It's fun to play } \\
\text { with the robot }\end{array}$ & \\
\hline & & $\begin{array}{l}\text { The robot looks } \\
\text { enjoyable }\end{array}$ & \\
\hline & & $\begin{array}{l}\text { The robot seems } \\
\text { charming }\end{array}$ & \\
\hline & & $\begin{array}{l}\text { The robot seems } \\
\text { boring }\end{array}$ & \\
\hline \multirow[t]{3}{*}{ SI } & Social Influence & $\begin{array}{l}\text { I think my } \\
\text { friends would } \\
\text { like me to use } \\
\text { the robot }\end{array}$ & $\begin{array}{l}\text { Heerink, M., } \\
\text { Kröse, B., } \\
\text { Evers, V. } \\
(2010) ; \\
\text { Pujadas- } \\
\text { Hostench, J., } \\
\text { Palau-Saumell, } \\
\text { R., } \\
\text { Forgas-Coll, S., } \\
\text { Sánchez- } \\
\text { García, J. } \\
\text { (2019) }\end{array}$ \\
\hline & & $\begin{array}{l}\text { I think it would } \\
\text { give a good } \\
\text { impression if I } \\
\text { played with the } \\
\text { robot }\end{array}$ & \\
\hline & & $\begin{array}{l}\text { I think that } \\
\text { people whose } \\
\text { opinion I value } \\
\text { would look } \\
\text { favourably } \\
\text { upon me } \\
\text { playing with } \\
\text { the robot }\end{array}$ & \\
\hline
\end{tabular}

\section{Appendix B}

\section{Cognitive questions}

The following is a series of cognitive exercises. Please answer each of the questions you think is the right answer.
- A baseball bat and a ball cost $€ 1.10$ in total. The bat costs 1 euro more than the ball. How much does the ball cost? cents

- If it takes 5 machines 5 min to make 5 pieces, how long would it take 100 machines to make 100 pieces? minutes

- In the middle of a lake there are water lilies. Every day, the area covered by the water lilies doubles its size. If the water lilies take 48 days to cover the entire lake, how long would it take for them to cover half the lake? ___ days

- If you are running a race and you pass the second person, where are you? position

- One farmer had 15 sheep and all but 8 died. How many are left? sheep

- Emily's father has three daughters. The first two are called April and May. What is the name of the third daughter? Is called

- How many cubic metres of earth are in a hole $3 \mathrm{~m}$ deep $\times$ $3 \mathrm{~m}$ wide $\times 3 \mathrm{~m}$ long? cubic metres

\section{References}

1. Guizzo E (2020) What is a robot?-ROBOTS: your guide to the world of robotics. https://robots.ieee.org/learn/what-is-a-robot/. Accessed 15 Nov 2020

2. Collier RM (1983) The word processor and revision strategies. Coll Compos Comm 34(2):149-155. https://doi.org/10. 2307/357402

3. Borsenik FD (1993) Hospitality technology in the 21st century. Hosp Res J 17(1):259-269. https://doi.org/10.1177/ 109634809301700121

4. Weber J (2005) Helpless machines and true loving care givers: a feminist critique of recent trends in human-robot interaction. J Inf Commun Ethics Soc 3(4):209-218

5. Ivanov S, Webster C, Berezina K (2017) Adoption of robots and service automation by tourism and hospitality companies. J Tour Dev 27(28):1501-1517

6. Pillinger A (2019) Gender and feminist aspects in robotics. GEECCO-Project (Gender Equality in Engineering trough Communication and Commitment). http://www.geecco-project. eu/fileadmin/t/geecco/Literatur/neu/Neu_30062020/Literatur_ Review_Gender_and_Robotics.pdf

7. Iancu I, Iancu B (2020) Designing mobile technology for elderly. A theoretical overview. Technol Forecast Soc Chang. https://doi. org/10.1016/j.techfore.2020.119977

8. Wang Y, Young JE (2014) Beyond "pink" and "blue": gendered attitudes towards robots in society. GenderIT 2014. https://dl. eusset.eu/handle/20.500.12015/2307

9. Market Reports World/2018 (2018) Global entertainment robots market research report-forecast to 2023. https://www. marketreportsworld.com/global-entertainment-robots-marketresearch-report-forecast-to-2023-12319119. Accessed 13 Feb 2020

10. Murphy J, Hofacker C, Gretzel U (2017) Dawning of the age of robots in hospitality and tourism: challenges for teaching and research. Eur J Tour Res 15:104-111

11. Nomura T (2017) Robots and gender. Gender Genome 1:18-26. https://doi.org/10.1089/gg.2016.29002.nom 
12. Bartneck C, Kanda T, Mubin O, Mahmud AA (2009) Does the design of a robot influence its animacy and perceived intelligence? Int J Soc Robot 1:195-204. https://doi.org/10.1007/s12369-0090013-7

13. De Graaf MM, Allouch SB (2013) Exploring influencing variables for the acceptance of social robots. Robot Auton Syst 61(12):1476-1486. https://doi.org/10.1016/j.robot.2013.07.007

14. Davis FD (1989) Perceived usefulness, perceived ease of use, and user acceptance of information technology. MIS Q 13:319-340. https://doi.org/10.2307/249008

15. Ajzen I, Fishbein M (1980) Understanding attitudes and predicting social behavior. Prentice-Hall, Englewood Cliffs

16. Bandura A (1986) The explanatory and predictive scope of selfefficacy theory. J Soc Clin Psychol 4(3):359-373. https://doi.org/ 10.1521/jscp.1986.4.3.359

17. Venkatesh V, Morris MG, Davis GB, Davis FD (2003) User acceptance of information technology: toward a unified view. MIS Q 27:425-478. https://doi.org/10.2307/30036540

18. Venkatesh V, Thong JYL, Xu X (2012) Consumer acceptance and use of information technology: extending the unified theory. MIS Q 36(1):157-178. https://doi.org/10.2307/41410412

19. Palau-Saumell R, Forgas-Coll S, Sánchez-García J, Robres E (2019) User acceptance of mobile apps for restaurants: an expanded and extended UTAUT-2. Sustainability 11(4):1210. https://doi.org/10.3390/su11041210

20. Reeves B, Nass CI (1996) The media equation: how people treat computers, television, and new media like real people and places. Cambridge University Press, Cambridge

21. Matarić MJ (2007) The robotics primer. MIT Press, London

22. De Graaf MM, Allouch SB, van Dijk JAGM (2019) Why would I use this in my home? A model of domestic social robot acceptance. Hum-Comput Interact 34(2):115-173. https://doi.org/10. 1080/07370024.2017.1312406

23. Heerink M, Kröse B, Evers V, Wielinga B (2010) Assessing acceptance of assistive social agent technology by older adults: the almere model. Int J Soc Robot 2:361-375. https://doi.org/10. 1007/s12369-010-0068-5

24. Turja T, Aaltonen L, Taipale S, Oksanen A (2020) Robot acceptance model for care (RAM-care): A principled approach to the intention to use care robots. Inf Manag 57(5):103220. https://doi. org/10.1016/j.im.2019.103220

25. Rea DJ, Wang Y, Young JE (2015) Check your stereotypes at the door: an analysis of gender typecasts in social human-robot interaction. International conference on social robotics. Springer, Cham, pp 554-563

26. Carpenter J, Davis JM, Erwin-Stewart N, Lee TR, Bransford JD, Vye N (2009) Gender representation and humanoid robots designed for domestic use. Int J Soc Robot 1(3):261-265. https:// doi.org/10.1007/s12369-009-0016-4

27. Bryant DA, Borenstein J, Howard A (2020) Why should we gender? The effect of robot gendering and occupational stereotypes on human trust and perceived competency. In: Proceedings of the 2020 ACM/IEEE international conference on human-robot interaction, pp 13-21

28. Suchman L (2006) Human-machine reconfigurations: plans and situated actions (2nd ed., Learning in doing: social, cognitive and computational perspectives). Cambridge University Press, Cambridge. https://doi.org/10.1017/CBO9780511808418

29. Chen NH, Huang SCT (2016) Domestic technology adoption: comparison of innovation adoption models and moderators. Hum Factors Ergonom Manuf Serv Ind 26(2):177-190. https://doi.org/ 10.1002/hfm.20621

30. Robertson J (2010) Gendering humanoid robots: robosexism in Japan. Body Soc 16(2):1-36. https://doi.org/10.1177/ $1357034 X 10364767$
31. Kuo IH, Rabindran JM, Broadbent E, Lee YI, Kerse N, Stafford RMQ, MacDonald BA (2009) Age and gender factors in user acceptance of healthcare robots. In: RO-MAN'09 Proceedings of 18th IEEE international symposium on robot and human interactive communication, Toyama, Japan, Piscataway, pp 214-219

32. Hines M (2011) Gender development and the human brain. Annu Rev Neurosci 34:69-88. https://doi.org/10.1146/annurev-neuro061010-113654

33. Ellemers N (2018) Gender stereotypes. Annu Rev Psychol 69:275-298. https://doi.org/10.1146/annurev-psych-122216011719

34. Evans JSBT, Stanovich KE (2013) Dual-process theories of higher cognition: advancing the debate. Perspect Psychol Sci 8(3):223-241. https://doi.org/10.1177/1745691612460685

35. Pennycook G, Rand DG (2019) Lazy, not biased: Susceptibility to partisan fake news is better explained by lack of reasoning than by motivated reasoning. Cognition 188:39-50. https://doi.org/10. 1016/j.cognition.2018.06.011

36. Gervais WM, Norenzayan A (2012) Analytic thinking promotes religious disbelief. Science 336:493-496. https://doi.org/10.1126/ science. 1215647

37. Young JE, Hawkins R, Sharlin E, Igarashi T (2009) Toward acceptable domestic robots: Applying insights from social psychology. Int J Soc Robot 1(1):95-108. https://doi.org/10.1007/ s12369-008-0006-y

38. Wirtz J, Lovelock C (2016) Services marketing: people, technology. World Scientific Publishing Company, Singapore

39. Andriella A, Torras C, Alenya G (2019) Short-term human-robot interaction adaptability in real-world environments. Int $\mathbf{J}$ Soc Robot. https://doi.org/10.1007/s12369-019-00606-y

40. Ye H, Jeong H, Zhong W, Bhatt S, Izzetoglu K, Ayaz H, Suri R (2019) The effect of anthropomorphization and gender of a robot on human-robot interactions. International conference on applied human factors and ergonomics. Springer, Cham, pp 357-362

41. Eyssel F, Hegel F (2012) (S) he's got the look: gender stereotyping of robots. J Appl Soc Psychol 42(9):2213-2230. https://doi.org/ 10.1111/j.1559-1816.2012.00937.x

42. Williams R, Edge D (1996) The social shaping of technology. Res Policy 25(6):865-899. https://doi.org/10.1016/00487333(96)00885-2

43. Gerrig RJ (2014) Psychology and life. Pearson New International Edition, Essex

44. Cervantes JA, Rodríguez LF, López S, Ramos F, Robles F (2016) Autonomous agents and ethical decision-making. Cogn Comput 8(2):278-296. https://doi.org/10.1007/s12559-015-9362-8

45. Johnson DO, Cuijpers RH, Pollmann K, van de Ven AA (2016) Exploring the entertainment value of playing games with a humanoid robot. Int J Soc Robot 8(2):247-269. https://doi.org/ 10.1007/s12369-015-0331-x

46. Belanche D, Casaló LV, Flavián C, Schepers J (2019) Service robot implementation: a theoretical framework and research agenda. Serv Ind J 40:203-225. https://doi.org/10.1080/ 02642069.2019 .1672666

47. Nomura T (2020) A possibility of inappropriate use of gender studies in human-robot interaction. AI Soc 35:751-754. https:// doi.org/10.1007/s00146-019-00913-y

48. Gong L, Nass C (2007) When a talking-face computer agent is half-human and half-humanoid: human identity and consistency preference. Hum Commun Res 33(2):163-193. https://doi.org/10. 1111/j.1468-2958.2007.00295.x

49. Breazeal C, Dautenhahn K, Kanda T (2016) Social robotics. In: Siciliano B, Khatib O (eds) Springer handbook of robotics. Springer handbooks. Springer, Cham

50. Fasola J, Mataric MJ (2012) Using socially assistive human-robot interaction to motivate physical exercise for older adults. Proc IEEE 100(8):2512-2526 
51. Savela N, Turja T, Oksanen A (2018) Social acceptance of robots in different occupational fields: a systematic literature review. Int J Soc Robot 10(4):493-502. https://doi.org/10.1007/s12369-0170452-5

52. Ghazali AS, Ham J, Barakova E, Markopoulos P (2020) Persuasive robots acceptance model (PRAM): roles of social responses within the acceptance model of persuasive robots. Int J Soc Robot 12:1075-1092. https://doi.org/10.1007/s12369-019-00611-1

53. Bröhl C, Nelles J, Brandl C, Mertens A, Nitsch V (2019) Human-robot collaboration acceptance model: development and comparison for Germany, Japan, China and the USA. Int J Soc Robot 11(5):709-726. https://doi.org/10.1007/s12369-01900593-0

54. Stock R M, Merkle M (2018) Can humanoid service robots perform better than service employees? A comparison of innovative behavior cues. In: Proceedings of the 51st Hawaii international conference on system sciences. http://hdl.handle.net/ $10125 / 50020$

55. Wirtz J, Patterson PG, Kunz WH, Gruber T, Lu VN, Paluch S, Martins A (2018) Brave new world: service robots in the frontline. J Serv Manag 29(5):907-931. https://doi.org/10.1108/JOSM-042018-0119

56. Putrevu S (2001) Exploring the origins and information processing differences between men and women: implications for advertisers. Acad Mark Sci Rev 10(1):1-14

57. Nomura T, Suzuki T, Kanda T, Kato K (2006) Measurement of negative attitudes toward robots. Interact Stud 7(3):437-454. https://doi.org/10.1075/is.7.3.14nom

58. Van der Heijden H (2004) User acceptance of hedonic information systems. MIS Q 28(4):695-704. https://doi.org/10.2307/ 25148660

59. Meyers-Levy J, Loken B (2015) Revisiting gender differences: what we know and what lies ahead. J Consum Psychol 25(1):129-149. https://doi.org/10.1016/j.jcps.2014.06.003

60. Ahuja MK (2002) Women in the information technology profession: a literature review, synthesis and research agenda. Eur J Inform Syst 11(1):20-34. https://doi.org/10.1057/palgrave.ejis. 3000417

61. Nickel K, Orth UR, Kumar M (2020) Designing for the genders: the role of visual harmony. Int J Res Mark 37(4):697-713. https:// doi.org/10.1016/j.ijresmar.2020.02.006

62. Chita-Tegmark M, Lohani M, Scheutz M (2019) Gender effects in perceptions of robots and humans with varying emotional intelligence. In: 2019 14th ACM/IEEE international conference on human-robot interaction (HRI), IEEE, pp 230-238

63. Tinbergen N (1963) On aims and methods of ethology. Z Tierpsychol 20:410-433. https://doi.org/10.1111/j.1439-0310. 1963.tb01161.x

64. Spets DS, Slotnick SD (2020) Are there sex differences in brain activity during long-term memory? A systematic review and fMRI activation likelihood estimation meta-analysis. Cogn Neurosci. https://doi.org/10.1080/17588928.2020.1806810

65. Costa PT Jr, Terracciano A, McCrae RR (2001) Gender differences in personality traits across cultures: robust and surprising findings. J Pers Soc Psychol 81(2):322-331. https://doi.org/10. 1037/0022-3514.81.2.322

66. Canli T, Desmond JE, Zhao Z, Gabrieli JD (2002) Sex differences in the neural basis of emotional memories. Proc Natl Acad Sci 99(16):10789-10794. https://doi.org/10.1073/pnas.162356599

67. Wood W, Eagly AH (2012) Biosocial construction of sex differences and similarities in behaviour. Adv Exp Soc Psychol 46:55-123. https://doi.org/10.1016/B978-0-12-394281-4.000027

68. Meyers-Levy J, Sternthal B (1991) Gender differences in the use of message cues and judgments. J Mark Res 28(1):84-96. https:// doi.org/10.2307/3172728
69. Tooby J, Cosmides L (2015) The theoretical foundations of evolutionary psychology. In: Buss D (ed) The handbook of evolutionary psychology. Pearson, Harlow, pp 1-85

70. Gracia-Ramos M, Huertas-Garcia R (2016) Decision making and erotic stimuli: an evolutionary perspective. Span J Mark-ESIC 20(1):30-40. https://doi.org/10.1016/j.reimke.2015.08.001

71. Hampson E, van Anders SM, Mullin LI (2006) A female advantage in the recognition of emotional facial expressions: test of an evolutionary hypothesis. Evol Hum Behav 27(6):401-416. https:// doi.org/10.1016/j.evolhumbehav.2006.05.002

72. Buss D (2014) Evolutionary psychology: The new science of the mind. Pearson New International Edition, Essex

73. Williams GC (1992) Natural selection: domains, levels, and challenges. Oxford University Press, Oxford

74. Hill K, Hurtado AM (1996) Ache life history. Walter de Gruyter, New York

75. Tanner NM (1983) Hunters, gatherers, and sex roles in space and time. Am Anthropol 85(2):335-341. https://doi.org/10.1525/aa. 1983.85.2.02a00040

76. DeVore I, Tooby J (1987) The reconstruction of hominid behavioral evolution through strategic modelling. In: Kinzey WG (ed) The evolution of human behavior: primate models. State University of New York, New York, pp 183-237

77. Silverman I, Choi J, Peters M(2007) The hunter-gatherer theory of sex differences in spatial abilities: data from 40 countries. Arch Sex Behav 36(2):261-268. https://doi.org/10.1007/s10508-0069168-6

78. Lawton CA, Morrin KA (1999) Gender differences in pointing accuracy in computer-simulated 3D mazes. Sex Roles 40(1):73-92. https://doi.org/10.1023/A:1018830401088

79. Vorvoreanu M, Zhang L, Huang Y H, Hilderbrand C, SteineHanson Z, Burnett M (2019) From gender biases to genderinclusive design: an empirical investigation. In: Proceedings of the 2019 CHI conference on human factors in computing systems, pp 1-14

80. Ono H, Zavodny M (2003) Gender and the internet. Soc Sci Q 84:111-121. https://doi.org/10.1111/1540-6237.t01-1-8401007

81. Hargittai E (2006) Differences in actual and perceived online skills: the role of gender. Soc Sci Q 87:432-448. https://doi.org/ 10.1111/j.1540-6237.2006.00389.x

82. Dittmar H, Long K, Meek R (2004) Buying on the internet: gender differences in on-line and conventional buying motivations. Sex Roles 50:423-444. https://doi.org/10.1023/B:SERS. 0000018896.35251.c7

83. Ford N, Miller D, Moss N (2001) The role of individual differences in Internet searching: an empirical study. J Am Soc Inf Sci Technol 52(12):1049-1066. https://doi.org/10.1002/asi.1165

84. Nomura T, Kanda T, Suzuki T, Kato K (2008) Prediction of human behavior in human-robot interaction using psychological scales for anxiety and negative attitudes toward robots. IEEE Trans Robot 24(2):442-451.https://doi.org/10.1109/TRO.2007.914004

85. Lin CH, Liu EZF, Huang YY (2012) Exploring parents' perceptions towards educational robots: gender and socio-economic differences. Br J Educ Technol 43(1):E31-E34. https://doi.org/ 10.1111/j.1467-8535.2011.01258.x

86. Lauriola M, Levin IP (2001) Personality traits and risky decisionmaking in a controlled experimental task: an exploratory study. Pers Indiv Differ 31(2):215-226

87. Buchan NR, Croson RT, Solnick S (2008) Trust and gender: an examination of behavior and beliefs in the investment game. J Econ Behav Organ 68(3-4):466-476. https://doi.org/10.1016/j. jebo.2007.10.006

88. Brunel FF, Nelson MR (2000) Explaining gendered responses to "help-self" and "help-others" charity ad appeals: the mediating role of world-views. J Advert 29(3):15-28. https://doi.org/10. 1080/00913367.2000.10673614 
89. Multu B, Osman S, Forlizzi J, Hodgins J, Kiesler S (2006) Task structure and user attributes as elements of human-robot interaction design. In: ROMAN 2006-The 15th IEEE international symposium on robot and human interactive communication. IEEE, pp 74-79

90. Heisz JJ, Pottruff MM, Shore DI (2013) Females scan more than males: a potential mechanism for sex differences in recognition memory. Psychol Sci 24(7):1157-1163

91. Croson R, Gneezy U (2009) Gender differences in preferences. J Econ Lit 47(2):448-474. https://doi.org/10.1257/jel.47.2.448

92. Hupfer ME, Detlor B (2006) Gender and web information seeking: a self-concept orientation model. J Am Soc Inf Sci Technol 57(8):1105-1115. https://doi.org/10.1002/asi.20379

93. Beck T, Behr P, Guettler A (2013) Gender and banking: are women better loan officers? Rev Financ 17(4):1279-1321. https://doi.org/ $10.1093 / \mathrm{rof} / \mathrm{rfs} 028$

94. Weiser EB (2000) Gender differences in Internet use patterns and Internet application preferences: a two-sample comparison. CyberPsychol Behav 3(2):167-178. https://doi.org/10.1089/ 109493100316012

95. Calabretta G, Gemser G, Wijnberg NM (2017) The interplay between intuition and rationality in strategic decision making: a paradox perspective. Organ Stud 38(3-4):365-401. https://doi. org/10.1016/S0191-8869(00)00130-6

96. Barr N, Pennycook G, Stolz JA, Fugelsang JA (2015) The brain in your pocket: evidence that smartphones are used to supplant thinking. Comput Hum Behav 48:473-480. https://doi.org/10.1016/j. chb.2015.02.029

97. Stanovich KE (2004) The robot's rebellion: finding meaning in the age of Darwin. University of Chicago Press, Chicago

98. Evans JSBT (2010) Intuition and reasoning: a dual-process perspective. Psychol Inq 21(4):313-326. https://doi.org/10.1080/ 1047840X.2010.521057

99. Wason PC, Evans JSBT (1975) Dual processes in reasoning? Cognition 3:141-154. https://doi.org/10.1016/0010-0277(74)900171

100. Dane E, Pratt MG (2007) Exploring intuition and its role in managerial decision making. Acad Manag Rev 32(1):33-54

101. Hodgkinson GP, Healey MP (2011) Psychological foundations of dynamic capabilities: reflexion and reflection in strategic management. Strategic Manag J 32(13):1500-1516. https://doi.org/ $10.1002 / \mathrm{smj} .964$

102. Pennycook G, Cheyne JA, Koehler DJ, Fugelsang JA (2016) Is the cognitive reflection test a measure of both reflection and intuition? Behav Res Methods 48:341-348. https://doi.org/10.3758/s13428015-0576-1

103. Todd M (2001) Fast and frugal heuristics for environmentally bounded minds. In: Gigerenzer G, Selten R (eds) Bounded rationality: the adaptive toolbox. The MIT Press, Cambridge, pp 51-70

104. Beilock SL, Carr TH (2001) On the fragility of skilled performance: what governs choking under pressure? J Exp Psychol-Gen 130(4):701-775. https://doi.org/10.1037//0096-3445.130.4.701

105. Kruglanski AW, Gigerenzer G (2011) Intuitive and deliberate judgments are based on common principles. Psychol Rev 118(1):97-109. https://doi.org/10.1037/a0020762

106. Thompson VA, Turner JP, Pennycock G (2011) Intuition, reason and metacognition. Cogn Psychol 63(3):107-140. https://doi.org/ 10.1016/j.cogpsych.2011.06.001

107. Toplak ME, West RF, Stanovich KE (2014) Assessing miserly information processing: an expansion of the cognitive reflection test. Think Reason 20(2):147-168. https://doi.org/10.1080/ 13546783.2013.844729

108. Raney AA (2004) Expanding disposition theory: reconsidering character liking, moral evaluations, and enjoyment. Commun Theory 14(4):348-369. https://doi.org/10.1111/j.1468-2885. 2004.tb00319.x
109. Oliver MB, Bartsch A (2010) Appreciation as audience response: exploring entertainment gratifications beyond hedonism. Hum Commun Res 36(1):53-81. https://doi.org/10.1111/j.1468-2958. 2009.01368.x

110. Vorderer P, Ritterfeld U (2009) Digital games. In: Nabi R, Oliver MB (eds) Sage handbook of media processes and effects. Sage, Thousand Oaks, pp 455-467

111. Lewis RJ, Tamborini R, Weber R (2014) Testing a dualprocess model of media enjoyment and appreciation. J Commun 64(3):397-416. https://doi.org/10.1111/jcom.12101

112. PAL Robotics (2020) Technical specifications of TIAGo robot. http://pal-robotics.com/robots/tiago/. Accessed 13 Feb 2020

113. Bentler P (2006) EQS structural equations program manual. Multivariate Software Inc, Encino

114. Hair JF, Black WC, Babin BJ, Anderson RE (2010) Multivariate data analysis. Pearson Prentice Hall, New Jersey

115. Gefen D, Straub D, Boudreau M (2000) Structural equation modeling and regression: guidelines for research practice. Commun Assoc Inf Syst. https://doi.org/10.17705/1CAIS.00407

116. Jang SH, Kim RH, Lee CW (2016) Effect of u-healthcare service quality on usage intention in a healthcare service. Technol Forecast Soc Chang 113:396-403. https://doi.org/10.1016/j.techfore. 2016.07.030

117. Ramírez-Correa P, Rondán-Cataluña FJ, Arenas-Gaitán J, MartínVelicia F (2009) Analysing the acceptation of online games in mobile devices: an application of UTAUT2. J Retail Consum Serv 50:85-93. https://doi.org/10.1016/j.jretconser.2019.04.018

118. Chiu CC, Wang ETG (2008) Understanding Web-based learning continuance intention: the role of subjective task value. Information and management 45(3):194-201. https://doi.org/10.1016/j. im.2008.02.003

119. Aymerich-Franch L, Ferrer I (2020) The implementation of social robots during the COVID-19 pandemic. arXiv preprint arXiv:2007.03941

120. Jackson RB, Williams T, Smith N (2020) Exploring the role of gender in perceptions of robotic noncompliance. In: Proceedings of the 2020 ACM/IEEE international conference on humanrobot interaction, pp 559-567. https://doi.org/10.1145/3319502. 3374831

121. Schermerhorn P, Scheutz M, Crowell CR (2008) Robot social presence and gender: Do females view robots differently than males? In: Proceedings of the 3rd ACM/IEEE international conference on human robot interaction, pp 263-270. https://doi.org/ $10.1145 / 1349822.1349857$

122. Crowelly CR, Villanoy M, Scheutzz M, Schermerhornz P (2009) Gendered voice and robot entities: perceptions and reactions of male and female subjects. In: Proceedings of 2009 IEEE/RSJ international conference on intelligent robots and systems, pp 3735-3741. https://ieeexplore.ieee.org/abstract/ document $/ 5354204$

123. Tay B, Jung Y, Park T (2014) When stereotypes meet robots: The double-edge sword of robot gender and personality in humanrobot interaction. Comput Hum Behav 38:75-84. https://doi.org/ 10.1016/j.chb.2014.05.014

Publisher's Note Springer Nature remains neutral with regard to jurisdictional claims in published maps and institutional affiliations.

Santiago Forgas-Coll has extensive experience in team management and coordination. He has been the rector's delegate for master's and postgraduate courses at the Faculty of Economics and Business at the University of Barcelona. He currently directs the business research group (UB). He is an Associate Professor in the Business Depart- 
ment, University of Barcelona. His main research interest cover all aspects of Artificial Intelligence and Social Robotics, digital marketing and services marketing, with a focus on consumer behavior. He has published articles in several international journals such as Industrial Management \& Data Systems, Online Information Review, Management Decision, Service Business, Journal of Business and Industrial Marketing, Tourism Management and Journal of Air Transport Management among many others.

Ruben Huerta-Garcia is a Serra-Húnter Associate Professor of marketing, University of Barcelona. His lines of research cover various topics related to market research, with emphasis on the methodology of experimental design and conjoint analysis, and its application to different areas of business management such as web design for tourism establishments, retail, brand management, tourism management and, more recently, social robotics. His work has been published in journals as Journal of Product \& Brand Management, Journal of Retailing and Consumer Services, Cornell Hospitality Quarterly, International Journal of Tourism Research, Journal of Business and Industrial Marketing and Industrial Management \& Data Systems among others.
Antonio Andriella is a Ph.D. candidate at IRI in the Perception and Manipulation Group. Since 2017, he has been holding a Marie Skłodowska-Curie Fellowship as part of an Innovative Training Network (ITN) called SOCRATES. Prior to coming to IRI, he worked in the AI industry for 7 years. His research interests are in the areas of human-robot interaction (HRI) and human-centered design technologies for older adults with cognitive impairments. His work focuses on designing, developing, and evaluating interactive social systems that personalize and adapt to their users over short-term and long-term interaction, based on individual needs and goals.

Guillem Alenyà director at the Institut de Robòtica i Informàtica Industrial (IRI), holds a tenured position at Spanish Scientific Research Council CSIC. He received a $\mathrm{PhD}$ degree (Doctor Europeus) from UPC in 2007 with a work on mobile robot navigation using active contours while he was supported by a EU-FP6 Marie-Curie scholarship. He has been visitor at KIT-Karlsruhe, INRIA-Grenoble and BRL-Bristol. He has coordinated numerous scientific and technological transfer projects involving image understanding, next-best-view, rule learning and plan execution tasks. He has published more than 100 articles in relevant venues in the areas of robotics, computer vision, and artificial intelligence. 